\title{
On the Dynamics of Hedge Fund Risk Exposures*
}

\author{
Andrew J. Patton ${ }^{\dagger}$ \\ Tarun Ramadorai ${ }^{\ddagger}$ \\ Duke University \\ University of Oxford
}

2 April 2010

\begin{abstract}
We propose a new method to capture changes in hedge funds' exposures to risk factors, exploiting information from relatively high frequency conditioning variables. Using a consolidated database of nearly 15,000 individual hedge funds between 1994 and 2009, we find substantial evidence that hedge fund risk exposures vary significantly across months. Our new method also reveals that hedge fund risk exposures vary within months, and capturing this variation significantly improves the fit of the model. The proposed method outperforms an optimal changepoint approach to capturing time-varying risk exposures, and we find evidence that there are gains from combining the two approaches. We find that the cost of leverage, the carry trade return and the recent performance of equity indices are the most important drivers of changes in hedge fund risk exposures.
\end{abstract}

Keywords: beta, time-varying risk, performance evaluation, structural breaks.

JEL Codes: G23, G11, C22.

${ }^{*}$ We thank the Oxford-Man Institute of Quantitative Finance for financial support, Alexander Taylor for dedicated research assistance, and Nick Bollen, Michael Brandt, Mardi Dungey, Jean-David Fermanian, Campbell Harvey, Olivier Scaillet, Kevin Sheppard, Melvyn Teo, and seminar participants at the Fuqua School of Business, the OxfordMan Institute Hedge Fund Conference, the CREST-HEC Hedge Fund Conference and the University of Tasmania for useful comments.

${ }^{\dagger}$ Department of Economics, Duke University, and Oxford-Man Institute of Quantitative Finance. 213 Social Sciences Building, Durham NC 27708-0097, USA. Email: andrew.patton@duke.edu.

${ }^{\ddagger}$ Saïd Business School, Oxford-Man Institute of Quantitative Finance and CEPR. Park End Street, Oxford OX1 1HP, UK. Email: tarun.ramadorai@sbs.ox.ac.uk. 


\section{Introduction}

An important feature of hedge funds is the speed at which they alter their investments in response to changing market conditions. Static analyses of hedge funds' risk exposures are likely to miss these rapid changes in their strategies or leverage ratios, and several new approaches have been proposed to overcome this difficulty. ${ }^{1}$ For example, Bollen and Whaley (2009) recommend the use of optimal changepoint regressions to estimate structural breaks in hedge fund factor loadings. An alternative approach, employed by Mamaysky, Spiegel and Zhang (2007) for mutual funds and also considered by Bollen and Whaley (2009) for hedge funds, is to use a Kalman filter-based model to track risk exposures as latent random variables.

One factor that must be taken into consideration when measuring changing hedge fund risk exposures is the high frequency (often daily or even higher) at which these changes occur. ${ }^{2}$ The approaches that have thus far been proposed to capture hedge funds' time-varying risk exposures are limited to tracking changes only at the monthly frequency, as this is the reporting frequency for all of the main hedge fund databases. To surmount this obstacle, we propose a new method to capture intra-month variation in hedge fund risk exposures, which uses as its starting point the widely-used Ferson and Schadt (1996) model to employ higher frequency conditioning information. To circumvent the lack of high frequency data on hedge fund performance, we posit a daily factor model for returns and then aggregate it up to the monthly frequency for estimation. We are thus able to employ monthly returns data and daily factor returns series to shed light on higher frequency variation in hedge fund returns. Using simulations as well as daily indices of hedge fund returns, we demonstrate that this technique is able to precisely track the dynamics of daily variation in hedge fund risk exposures.

Employing returns data on a cross-section of 14,194 individual hedge funds and funds-of-funds over the period 1994 to 2009, we find that our proposed method performs very well at describing the dynamics of hedge fund returns. In particular, we show that the proposed model generates

\footnotetext{
${ }^{1}$ The literature on modeling hedge fund returns using static models is extensive. A partial list includes Fung and Hsieh (1997, 2004a,b), Ackermann, McEnally and Ravenscraft (1999), Liang (1999), Agarwal and Naik (2004), Kosowski, Naik and Teo (2006), Agarwal, Fung, Loon, and Naik (2009), Chen and Liang (2007), Fung, Hsieh, Naik and Ramadorai (2008), Patton (2009) and Jagannathan, Malakhov and Novikov (2010).

${ }^{2}$ See "Wall Street's New Race Toward Danger", Barron's, March 8, 2010 and "Traders Piqued By the Picosecond, But Physics Intervenes," Wall Street Journal, March 10, 2010.
} 
adjusted $R^{2}$ statistics that are a substantial improvement over both a static-parameter benchmark model and the optimal changepoint approach recently proposed by Bollen and Whaley (2009), with the improvements in adjusted $R^{2}$ s being $13 \%$ and $6 \%$ respectively. We also find that the inclusion of higher frequency conditioning information is an important contributor to the performance of our model. The percentage of funds for which we find statistically significant factor exposure variation rises from $14.9 \%$ to $23.4 \%$ when we include daily information as well as monthly information in our estimated specifications. In short, we find that incorporating monthly and daily information substantially improves our ability to detect variations in hedge fund risk exposures.

The advantages conferred by our approach are not merely statistical. Our model has the added benefit of aiding economic interpretation of the variation in factor loadings that we estimate, a contribution relative to the existing models in the literature. We conduct a relatively wide search across economically-motivated conditioning variables to help us to capture the variation in hedge fund risk exposures. ${ }^{3}$ We find that two out of the three most frequently selected interaction variables are returns on the Dollar/Yen carry trade, and changes in short-term interest rates. We interpret this as evidence of the significant impact on hedge fund risk exposures of variation in the costs of leverage. This adds to the growing evidence (Liang (1999) and Khandani and Lo (2008)) on the role that leverage plays in explaining hedge fund returns. We also find evidence that returns on the NASDAQ and the S\&P 500, are important factors driving hedge fund factor loadings.

Finally, we analyze the implications of our method for performance measurement. We find that, across funds with significantly time-varying factor exposures, annualized alpha rises on average by half a percent when estimated using our model rather than the constant model. This is similar to the earlier findings of Ferson and Schadt (1996), which helped to redeem the performance of mutual fund managers relative to earlier estimates of their alphas from static factor models. However this finding masks much bigger changes at the individual fund level - we find a mean absolute difference of $4.6 \%$ between annualized alphas estimated using the constant model and our time-varying exposure model.

The outline of the paper is as follows. The remainder of this section situates our paper in the

\footnotetext{
${ }^{3}$ Of course, as noted by Ferson and Schadt (1996), Sullivan, Timmermann and White (1999), Ferson, Sarkissian and Simin (2008) and others, incorrect inferences about the significance of the "best" model will be obtained if this search process is ignored; this is the classic data snooping problem. As in Sullivan et al., for example, we employ the bootstrap reality check of White (2000) to control for this search.
} 
literature on the dynamic performance evaluation of managed investments. Section 2 describes our modelling approach and Section 3 describes the data used in our analysis. Section 4 presents analyses which verify that our proposed method works well in practice, Section 5 presents our main empirical results, and Section 6 checks the results for robustness. Finally, Section 7 concludes.

\section{$1.1 \quad$ Related literature}

Our paper contributes to the literature on dynamic performance measurement for actively managed investment vehicles. An intellectual predecessor of our approach is Ferson and Schadt (1996), who use well-known predictors of returns as proxies for publicly available information, and use these instruments to estimate an unconditional version of their conditional model for the performance evaluation of mutual funds. ${ }^{4}$ Their model uses only monthly data, and is related to Jagannathan and Wang (1996), who focus on risk adjustments for equities rather than performance evaluation. ${ }^{5}$ The conditioning information used by Ferson and Schadt is lagged one month so as to capture only predetermined information; the interpretation of the alphas that they estimate is as the excess return earned by managers over and above that which could be generated by a managed portfolio strategy that used only public information to generate returns. The approach in Ferson and Schadt (1996) is extended by Christophersen, Ferson and Glassman (1998) to include the possibility of time-variation in alpha. These authors detect performance persistence amongst the most poorly performing mutual funds with greater precision than static models.

As in Ferson and Schadt (1996), we estimate a conditional performance evaluation model. Our contribution lies in our use of daily conditioning information for the evaluation of monthly reported performance. There have been other attempts to combine monthly returns and intramonthly information to ascertain the higher-frequency variation in risk factor loadings, following an influential paper by Goetzmann, Ingersoll and Ivkovic (2000), which shows that HenrikssonMerton timing measures (discussed below) estimated from monthly data are biased in the presence of daily timing ability. Goetzmann et al. attempt to correct for this bias by cumulating daily put values on the S\&P 500 for each month in their sample, and they incorporate it as an additional regressor in their market-timing specifications. Ferson and Khang (2002) also present a conditional

\footnotetext{
${ }^{4}$ Chen and Knez (1996), in a contemporaneous paper, derive related insights about conditional performance evaluation.

${ }^{5}$ Related literature includes, but is not limited to, Ferson and Harvey (1991) and Evans (1994).
} 
version of the holdings-based performance evaluation method that avoids the Goetzmann et al. bias. Our approach provides a new alternative to the methods followed in these papers; we posit a daily model for hedge fund returns, which we time-aggregate and estimate at the monthly frequency. We also search over a wide array of conditioning variables, and rigorously account for the search using the reality check bootstrap. Our aggregation of a daily factor model up to a monthly model is similar in spirit to Ferson, Henry and Kisgen (2006), who study government bond funds and consider an underlying continuous-time process for the term structure of interest rates.

It is worth briefly mentioning an earlier set of related models which also use conditioning information to detect time-variation in managerial risk exposures, but with a somewhat different goal. Treynor and Mazuy (1966) proposed an extension to the standard single factor market model which included a quadratic term in an effort to detect whether fund volatility rose when the market was performing well. The quadratic regression can be also motivated using the model of Admati, Bhattacharya, Pfleiderer and Ross (1986), in which a successful market-timing fund manager receives a noisy signal about the one period ahead market return. Such quadratic regressions have also been used by Lehmann and Modest (1987) in the context of mutual funds, and by Chen and Liang (2007) to describe the market timing ability of hedge funds. The idea has also been generalized to consider private signals about market attributes such as future market liquidity (see Cao, Chen and Liang (2009)). Another popular timing specification is that of Henriksson and Merton (1981), who extend the standard single factor market model by including an interaction between the market return and an indicator variable for when the market return is positive. The distinguishing feature of this class of models relative to the conditional performance evaluation models discussed earlier is the use of contemporaneous information on the conditioning variables. As a consequence of the use of this information, these models have two measures of managerial ability. The first, which the literature commonly refers to as 'timing', is the coefficient on the interaction term between the factor and the contemporaneous variable representing the signal (in the case of pure market timing, the signal would just be the factor plus noise, giving rise to the quadratic model). The second is the intercept that comes from the unconditional estimation of the conditional model. This is no longer the only measure of performance, but rather the 'selectivity' of the fund. ${ }^{6}$ In contrast, as we only

\footnotetext{
${ }^{6}$ Holdings-based performance evaluation approaches have also been used to separate timing ability from selectivity (See Daniel, Grinblatt, Titman and Wermers (1997), Chen, Jegadeesh and Wermers (2000), and Da, Gao and Jagannathan (2009)). Graham and Harvey (1996) use asset allocation recommendations in investment newsletters
} 
use lagged conditioning information in this paper, the alphas which we estimate are interpretable as measures of fund performance over and above that which can be garnered using public information signals. Our estimated alphas are, therefore, measures of managerial ability in the usual manner.

Finally, our use of daily returns on hedge fund indices to validate our technique (see Section 4) adds to the sparse literature which uses daily data on investment managers' returns to measure their performance. Busse (1999) finds that mutual funds have significant volatility timing ability using daily returns data. Bollen and Busse (2001), also using daily data, confirm that mutual funds have significant market timing ability. Chance and Hemler (2001) use daily executed recommendations of market-timers, and find that they have significant daily timing ability which vanishes when their performance is evaluated at the monthly frequency.

\section{Modelling time-varying hedge fund risk exposures}

A variety of methods have been proposed in the literature for capturing time-varying risk exposures

of hedge funds, see Bollen and Whaley (2009) for a recent review. In this section we first describe the modelling approach advocated by Bollen and Whaley, namely, an "optimal changepoint" model, and then introduce our method to capture time-variation in factor loadings. To simplify the discussion of the various approaches we consider a simple one-factor model for capturing risk exposures, although in our empirical analysis in Section 5 we allow for multiple factors.

\subsection{Changepoint models for hedge fund returns}

A simple but effective approach for capturing dynamic hedge fund risk exposures used by Bollen and Whaley (2009) is the optimal changepoint regression of Andrews, et al. (1996). This approach models beta as constant between changepoints, with abrupt changes to a new value at the changepoints. The theory in Andrews, et al. (1996) allows the researcher to consider many changepoints but in the interests of parsimony Bollen and Whaley (2009) allow for the presence of just a single changepoint for each fund (although the time of the changepoint can differ across funds). Thus this model for hedge fund returns is:

$$
r_{i t}=\alpha_{i}+\alpha_{i}^{0} \cdot \mathbf{1}\left(t \leq \tau_{i}^{*}\right)+\beta_{i} f_{t}+\beta_{i}^{0} f_{t} \cdot \mathbf{1}\left(t \leq \tau_{i}^{*}\right)+\varepsilon_{i t}
$$

to evaluate whether they help investors to time the market. 
where $r_{i t}$ is the return on hedge fund $i$ in month $t, f_{t}$ is the return on the factor in month $t$, and $\mathbf{1}\left(t \leq \tau_{i}^{*}\right)$ is an indicator for whether the time period $t$ is before the changepoint $\tau_{i}^{*}$. Testing for the significance of the change in risk exposures in a changepoint regression is complicated by the fact that the date of the change, $\tau_{i}^{*}$, is estimated at the same time as the pre- and post-change parameters. Having searched across all possible dates for the most likely date of a change, it is no longer appropriate to use a standard $F$-test to test for the significance in the change in the parameters. Instead, non-standard asymptotic critical values or bootstrap critical values must be used to determine the significance of the change. We describe a bootstrap approach in Section 2.4 below.

\subsection{Models with monthly variation in risk exposures}

A simple but economically interpretable alternative to the change-point approach discussed above is a model for time-varying betas based on observable conditioning variables, which as discussed above is used by Ferson and Schadt (1996) for mutual funds. In this approach, the betas are specified to evolve as a linear function of observable variables measured monthly:

$$
\begin{aligned}
r_{i t} & =\alpha_{i}+\beta_{i t} f_{t}+\varepsilon_{i t} \\
\text { where } \beta_{i t} & =\beta_{i}+\gamma_{i} Z_{t-1}
\end{aligned}
$$

That is, the return on fund $i$ is driven by a factor, $f_{t}$, with the factor loading varying according to some zero-mean variable $Z_{t-1} \cdot{ }^{7}$ Substituting in the equation for $\beta_{i t}$ we obtain the following:

$$
r_{i t}=\alpha_{i}+\beta_{i} f_{t}+\gamma_{i} f_{t} Z_{t-1}+\varepsilon_{i t}
$$

which is easily estimated using OLS regression. ${ }^{8}$ Note that the constant-beta model is nested in the above specification, and the significance of time variation in beta for the $i^{\text {th }}$ fund can be tested via a standard Wald test of the following hypothesis:

$$
H_{0}^{(i)}: \gamma_{i}=0 \text { vs. } H_{a}^{(i)}: \gamma_{i} \neq 0
$$

\footnotetext{
${ }^{7}$ De-meaning $Z_{t-1}$ (which we can easily impose in practice) ensures that we can interpret $\beta_{i}$ as the average level of risk exposure. Using $Z_{t-1}$ rather than $Z_{t}$ means that we can interpret $\alpha_{i}$ as a measure of the fund's risk-adjusted performance, as discussion in Section 1.1.

${ }^{8}$ Standard errors that are robust to heteroskedasticity and non-normality should be used in place of the usual OLS standard errors, to account for these features of hedge fund returns, and we do so in the empirical implementation below.
} 
As discussed above, Ferson and Schadt (1996) find that capturing variation in risk exposures via observable variables at the monthly frequency improves the accuracy of factor models such as those above. Mamaysky, et al. (2008) also find that adding observable variables to their model for mutual fund returns improves its performance, relative to a model solely with a latent factor driving variation in risk exposures. Cao, et al. (2009) find that monthly measures of liquidity are able to explain some of the changes in the market exposures of hedge funds.

\subsection{Models with daily variation in risk exposures}

Many hedge funds alter or turn over positions very frequently, thus it is possible that a hedge fund's risk exposure changes substantially within a month. This observation necessitates an extension of the above approach to modelling time-varying risk exposures. Consider the daily returns on hedge fund $i$, denoted $r_{i d}^{*}$, and a corresponding daily factor model for these returns:

$$
r_{i d}^{*}=\alpha_{i}+\beta_{i d} f_{d}^{*}+\varepsilon_{i d}^{*}
$$

Let us assume that the factor loadings for this fund vary as a function of some factor, $Z$, which is observable at a daily frequency. Let $Z_{d}^{*}$ denote this variable measured at the daily frequency and $Z_{d}$ denote this variable measured at the monthly frequency (that is, $Z_{d}$ will be constant within each month and jump to a new level at the start of each month).

$$
\beta_{i d}=\beta_{i}+\gamma_{i} Z_{d-1}+\delta_{i} Z_{d-1}^{*}
$$

Substituting in we obtain a simple interaction model for daily hedge fund returns:

$$
r_{i d}^{*}=\alpha_{i}+\beta_{i} f_{d}^{*}+\gamma_{i} f_{d}^{*} Z_{d-1}+\delta_{i} f_{d}^{*} Z_{d-1}^{*}+\varepsilon_{i d}^{*}
$$

Returns on individual hedge funds are currently only available monthly, and so to estimate this model we need to aggregate returns from the daily frequency up to the monthly frequency. ${ }^{9}$ Define the monthly return on fund $i$ as:

$$
r_{i t} \equiv \sum_{d \in \mathcal{M}(t)} r_{i d}^{*}
$$

where $\mathcal{M}(t)$ is the set of days in month $t$. Define $f_{t}$ and $Z_{t}$ similarly, and let $n(t)$ denote the number of days in month $t$. Then the specification for monthly hedge fund returns becomes:

\footnotetext{
${ }^{9}$ We use log-returns, so the monthly return is simply the sum of the daily returns.
} 


$$
r_{i t}=n(t) \alpha_{i}+\beta_{i} f_{t}+\gamma_{i} f_{t} Z_{t-1}+\delta_{i} \sum_{d \in \mathcal{M}(t)} f_{d}^{*} Z_{d-1}^{*}+\varepsilon_{i t}
$$

Note that the dependent variable above is now the monthly return on hedge fund $i$, and all variables on the right-hand side are also measured monthly. The new variable that appears in this specification relative to the Ferson-Schadt style specification in equation (3) is of the form $\sum f_{d}^{*} Z_{d-1}^{*}$. This is a monthly aggregate of a daily interaction term, and it captures variations in hedge fund risk exposures at the daily frequency. If the factor, $f_{d}^{*}$, and the conditioning variable, $Z_{d-1}^{*}$, are both available at the daily frequency, then under the assumption that $\varepsilon_{i d}^{*}$ is serially uncorrelated and uncorrelated with $f_{s}^{*}$ for all $(d, s)$ we are able to estimate the coefficients of this model using standard OLS. As above, for valid statistical inference we need to account for potential heteroskedasticity and non-normality in the residuals. In Section 4 we present analyses based on real daily hedge fund index returns and on simulated returns that confirm that this modeling approach works well in realistic applications.

The constant-beta model is nested in the above specification, and the significance of time variation in beta can be tested via a standard Wald test of the following hypothesis:

$$
H_{0}^{(i)}: \gamma_{i}=\delta_{i}=0 \quad \text { vs. } \quad H_{a}^{(i)}: \gamma_{i} \neq 0 \cup \delta_{i} \neq 0
$$

Furthermore, we can test whether we find significant evidence of daily variation in hedge fund risk exposures, controlling for monthly variation, by testing that the coefficient on the daily interaction term is zero:

$$
H_{0}^{(i)}: \delta_{i}=0 \quad \text { vs. } \quad H_{a}^{(i)}: \delta_{i} \neq 0
$$

While it is anticipated that hedge funds do adjust their risk exposures within the month, our ability to detect those changes depends on whether we can find observable daily interaction variables, $Z_{d}^{*}$, that are correlated with those changes.

\subsection{Bootstrap tests}

Inference on the above models involves non-standard econometric methods. The optimal changepoint model is estimated by searching over all possible dates for the changepoint, invalidating standard $F$-tests for the significance of the changepoint. As discussed in detail in Section 3 below, our approach based on observable conditioning information also involve searches, this time across 
an array of possible conditioning variables. The approach of searching for the best-fitting conditioning variable and then testing its significance via a standard $F$-test suffers from data snooping bias, see White (2000) for example. To obtain valid critical values for tests for these models we employ a bootstrap approach.

\subsubsection{Testing the significance of the changepoint}

To test the significance of a changepoint for a given fund, we search across all possible changepoint dates for the one that maximizes the fit, and record the $F$-statistic associated with that date (this is the "supF" statistic of Andrews, et al. (1996)). In the absence of a search across dates this statistic would have an $F$ distribution. However when we search across all possible dates this statistic no longer has an $F$ distribution and we instead compute its critical value via the bootstrap. We use a parametric bootstrap with samples drawn according to the stationary bootstrap of Politis and Romano (1994). To bootstrap data under the null hypothesis of no significant changepoint we first estimate the constant-parameter factor model on a hedge fund's returns, and save the estimated parameter vector and the regression residuals. We then create bootstrap samples of returns for this hedge fund imposing the null of no change in the parameter vector

$$
r_{i, s_{b}(t)}^{(b)} \equiv \hat{\alpha}_{i}+\hat{\beta}_{i} f_{s_{b}(t)}+\varepsilon_{i, s_{b}(t)}
$$

where $\left(\hat{\alpha}_{i}, \hat{\beta}_{i}\right)$ are the parameter estimates from the original data, $b$ is an indicator for the bootstrap number (running from $b=1$ to $B$ ) and $s_{b}(t)$ is the new time index which is a random draw from the original set $\{1, . ., T\}$. Serial dependence in returns is captured by drawing returns data in blocks with starting point and length both random. Following Politis and Romano (1994), the block length is drawn from a geometric distribution, with a parameter $q_{S B}$ that controls the average length of each block. In our empirical work we set $q_{S B}=3$. Each bootstrap sample is the same length as the original sample for the fund. For each set of bootstrapped data we search across all possible break dates for the one that maximizes the fit, and record the $F$-statistic associated with that date. The $90^{t h}$ percentile of the distribution of this statistic across the $B=1,000$ bootstrap samples serves as the 0.10 level critical value for the test of no significant changepoint. If the supF statistic for a given fund is larger than this fund-specific critical value, then we have significant evidence of a 
change in the parameters of this model for that fund. ${ }^{10}$

\subsubsection{Controlling for the search across potential conditioning variables}

As noted by Ferson and Schadt (1996), Sullivan, Timmermann and White (1999), and Ferson, Sarkissian and Simin (2008), it is critical to take into account the search across potential conditioning variables when conducting tests of the significance of the "best" model. We follow Sullivan, et al. (1999) and test the significance of the best-fitting conditioning variable by using the "reality check" of White (2000), again employing the stationary bootstrap of Politis and Romano (1994). The test statistic for this approach is the smallest $p$-value, across all potential conditioning variables, from a joint test of the significance of all coefficients on interaction variables, as in the hypotheses in equation (10). To obtain critical values that are valid in the face of our search across many possible interaction variables we bootstrap both the hedge fund return and the factor returns, and estimate the interaction model in equation (9). As in White (2000), to impose the null hypothesis that the interaction terms have zero coefficients we re-center the parameters estimated on the bootstrap data by subtracting the actual estimated values of these parameters. We then compute $p$-values for the joint test of significance of the interaction terms, and store the smallest of these across all interaction variables considered. The $10^{t h}$ percentile of the distribution of this statistic across the 1,000 bootstrap samples serves as the 0.10 level critical value for the test of no significant interaction variables. If the smallest $p$-value observed on our real data is smaller than this critical value then we have evidence of a significant interaction variable, controlling for our search across many possible variables.

\section{Data}

\subsection{Hedge fund and fund of funds data}

We use a large cross-section of hedge funds and funds-of-funds over the period from January 1994 to June 2009, which is consolidated from data in the HFR, CISDM, TASS, Morningstar and BarclayHedge databases. Appendix A contains details of the process followed to consolidate these data. The funds in the combined database come from a broad range of vendor-classified strategies, which

\footnotetext{
${ }^{10}$ In our empirical work we also computed the "avgF", and "expF" statistics in Andrews, et al. (1996) and found little difference in the results of the tests when applied to our hedge fund data.
} 
are consolidated into ten main strategy groups: Security Selection, Global Macro, Relative Value, Directional Traders, Funds of Funds, Multi-Process, Emerging Markets, Fixed Income, CTAs and Other (this category contains funds with missing vendor strategy classifications). The set contains both live and dead funds, the percentage of the funds in the data that are live and dead is reported in Table A.1. in the Appendix. The distribution of live versus defunct funds is roughly similar across the databases, and the total percentage of defunct funds is $46 \%$, which is comparable to the ratio reported in Agarwal, Daniel and Naik (2009) of 48\%, although their sample period ends in 2002.

Table I reports summary statistics on the hedge fund data. To overcome the well-known problem of return smoothing in monthly reported hedge fund returns, we use "unsmoothed" returns in our analysis, which are estimated from the raw returns using the Getmansky, Lo and Makarov (2004) moving average model. The parameters of this model are estimated separately for each individual fund, and as in Getmansky, et al. (2004) we use two lags. (In Section 6 we check the sensitivity of our results to using four lags, or using zero lags, which corresponds to using raw returns.) The means of the reported returns and unsmoothed returns are similar, but as expected the distribution of the "unsmoothed" returns is slightly more disperse. The median fund has assets under management of USD 32MM, while the mean is much larger, at USD 167MM, reflecting the significantly skewed size distribution that several other studies (Getmansky (2004), Teo (2010)) have highlighted. The median management fee is $1.5 \%$, and the median incentive fee is $20 \%$, consistent with earlier literature (Agarwal, Daniel and Naik (2009)); and the withdrawal restrictions (lockup \& redemption notice periods) are also comparable to earlier literature (Aragon (2005)). Panel B of the table shows that the lengths of the return histories for the funds in the sample correspond closely to that reported by Bollen and Whaley (2009), with around half of our funds having 5 or more years of data available, and around $17 \%$ of our funds having less than 3 years of data. Finally, Panel C reports the distribution of funds across strategies: the two largest strategies are Security Selection (20.8\%) and Funds of Funds (23.3\%), while the two smallest strategies (not including 'Other,' which captures those funds with unreported strategies) are Relative Value (1.0\%) and Emerging Markets (3.4\%). Given that our complete sample contains 14,194 individual funds, even the smallest strategy group has 146 distinct hedge funds, which enables us to undertake relatively precise strategy-level analyses. 


\subsection{Hedge fund factors}

The second set of data that we employ is on factor returns. Throughout our analysis, we model the risks of hedge funds using the seven-factor model of Fung and Hsieh (2004a). These seven factors have been shown to have considerable explanatory power for fund-of-fund and hedge fund returns, see Fung and Hsieh $(2001,2004 a, b)$, and have been used in numerous previous studies, see Bollen and Whaley (2009), Teo (2009) and Ramadorai (2009). The set of factors comprises the excess return on the S\&P 500 index (SP500); a small minus big factor (SMB) constructed as the difference between the Wilshire small and large capitalization stock indices; the excess returns on portfolios of lookback straddle options on currencies (PTFSFX), commodities (PTFSCOM), and bonds (PTFSBD), which are constructed to replicate the maximum possible return to trendfollowing strategies on their respective underlying assets; ${ }^{11}$ the yield spread of the U.S. 10-year Treasury bond over the 3-month T-bill, adjusted for the duration of the 10-year bond (TCM10Y); and the change in the credit spread of Moody's BAA bond over the 10-year Treasury bond, also appropriately adjusted for duration (BAAMTSY).

\subsection{Variables associated with changes in risk exposures}

We consider a variety of different variables that may be associated with hedge fund managers' decisions to increase or decrease their exposure to systematic risks. These variables can be categorized into four broad groups, corresponding to the underlying drivers of liquidity, funding and leverage, volatility and performance.

\subsubsection{Liquidity}

There is a growing recognition of the impact of liquidity on hedge fund and mutual fund performance. Pollet and Wilson (2008) document that mutual funds rarely diversify in response to increases in their asset base, and associate their result with limits to the scalability of fund portfolios, such as price impact or liquidity constraints. Aragon (2005) and Sadka (2009) both find that liquidity risk is an important determinant of hedge fund returns, and one that is not captured by the Fung-Hsieh (2004a) seven factors. Following the recent work of Cao, et al. (2009) we consider

\footnotetext{
${ }^{11}$ See Fung and Hsieh (2001) for a detailed description of the construction of these primitive trend-following (PTF) factors.
} 
the case that managers may attempt to time their exposure to risk factors in such a manner as to mitigate the influence of price impact. As liquidity rises (falls), the absolute magnitude of risk exposures will rise (fall) as funds more (less) frequently enter or exit positions.

To capture systematic time-series variation in asset market liquidity at both monthly and daily frequencies we employ two measures: The first is NYSE turnover, measured as the ratio of the aggregate volume traded in dollars each day or month, divided by the aggregate market capitalization of the stocks at the close of the day or month. ${ }^{12}$ The second is the 'Amivest' measure, which is the absolute return each day or month on the $\mathrm{S} \& \mathrm{P} 500$ index divided by the trading volume on the S\&P 500 in dollars, measured at the same frequency. This is used as a measure of liquidity by Amihud, Mendelson and Lauterbach (1997) and Amihud (2002) among others.

\subsubsection{Funding and leverage}

Mechanically, hedge fund managers' exposures to systematic risk factors will vary with the level of leverage that they employ, if their long and short positions do not exactly offset one another along the dimension of factor exposure (see Rubin, Greenspan, Levitt and Born (1999) who document that hedge funds take on significant leverage). The leverage available to hedge funds will vary with the costs of borrowing, which we capture using several measures. First, we compute level (the constant maturity three month T-bill rate), slope (the difference between the ten-year T-bond and three month T-bill rates) and curvature (twice the two-year rate less the three-month rate less the ten-year rate) factors for the U.S., and use their first differences as conditioning variables. To capture variation in the availability of credit on account of changes in the probability of default, we also include the level of the credit spread of Moody's BAA bond over the 10-year Treasury bond, adjusted for duration. We also include the TED spread (the 3-month LIBOR rate minus the 3-month T-bill rate), as a measure of funding liquidity following Garleanu and Pedersen (2009), and the USD/JPY carry trade return (change in the spot exchange rate less the interest differential) to capture variation in the cost of funding of borrowings in Japan.

\footnotetext{
${ }^{12}$ Griffin, Nardari and Stulz (2007) employ a similar measure of liquidity, and Hasbrouck (2009) provides evidence that volume-based liquidity measures are able to capture time-variation in liquidity better than price-based measures.
} 


\subsubsection{Volatility}

As financial market volatility rises, hedge fund managers wishing to maintain fund return volatility constant may trim risk exposures, as per the example of Ferson and Schadt (1996). We therefore include several measures of underlying asset volatility. First, we use the VIX index (see Whaley (2000)), which is a measure of volatility extracted from the prices of options on the S\&P 500 index. We also use two measures of "realized volatility" (RV) based on intra-daily data, one on the S\&P 500 index and the other on the USD/JPY exchange rate. ${ }^{13}$ Finally, we also include the variance risk premium on the S\&P 500 index, computed using both option-implied and realized volatility as in Todorov (2009), which measures the sensitivity of investors to volatility in this index.

\subsubsection{Performance}

Several papers on hedge funds have debated the role of incentive-alignment mechanisms such as high-water marks on hedge fund risk-taking behavior. When a fund makes low or negative returns, it is more likely to be under its high-water mark, and consequently, managers may have incentives to increase their levels of systematic risk, see Goetzmann, Ingersoll and Ross (2003), and vice versa. ${ }^{14}$ We therefore include the fund's recent performance (past one-month and past threemonth returns) as conditioning variables. (Note that these two variables are only available at the monthly frequency.) Further, hedge fund managers are often implicitly or explicitly benchmarked to commonly available indices. When the returns on these benchmarks are high, managers may be tempted to increase their risk-factor loadings to avoid the perception that they are underperforming, and vice versa. With this in mind, we also include returns on the S\&P 500, the NASDAQ, SMB, HML and the Momentum factor (UMD) as possible conditioning variables.

All told, we have a set of 19 possible conditioning variables in our set: $\Delta$ Level, $\Delta$ Slope, $\Delta$ Curvature, Default Spread, TED Spread, USD/JPY Carry Trade Return, Fund Performance (past month), Fund Performance (past quarter), S\&P 500 Return, NASDAQ Return, SMB, HML,

\footnotetext{
${ }^{13}$ These realized volatilities are based on 5-minute prices and were obtained from the Oxford-Man Institute's "Realized Library" data, available at http://realized.oxford-man.ox.ac.uk/. See Heber, et al. (2009) for details on how these measures are computed. The S\&P 500 RV series is available from January 1996 until February 2009, and the USD/JPY RV series is available from January 1999 to February 2009. Outside of these periods we use the simple squared returns on these series as the volatility measure.

${ }^{14}$ However Panageas and Westerfield (2009) analyze high water mark contracts as a sequence of options with a changing strike price, and do not find risk-shifting problems in their setup.
} 
UMD, Turnover, Amivest, VIX, Variance Risk Premium, S\&P 500 realized volatility and USD/JPY spot rate realized volatility. The last six of the above variables are at least moderately serially correlated, and some are strongly serially correlated. For each of these six variables we use a simple exponentially weighted moving average (EWMA) model to obtain their "surprise" component, and use this in place of the levels of these variables. ${ }^{15}$

\section{The accuracy of estimates of daily betas using monthly returns}

In this section we study the accuracy of our proposed method for estimating daily variations in the factor exposures of hedge funds using only monthly returns on these funds. We analyze this problem in two ways, and we find support for our method in both cases. Data on individual hedge fund returns is almost invariably available only at the monthly frequency, however daily data on a collection of hedge fund style index returns has recently become available. These daily index returns are an ideal, real-world dataset on which to check the accuracy of our method. Our first approach is to employ this daily data on hedge fund index returns, and to compare the results that are obtained when estimating the model on daily data with those that are obtained when using our method on the monthly returns on these indices. Second, we conduct a simulation study that is calibrated to match the key features of hedge fund returns, and study the accuracy of the proposed method in this setting. In this analysis we check the robustness of our estimation method to different features of the return-generating process.

\subsection{Results using daily hedge fund index returns}

Daily returns on hedge fund style indices have recently become available from Hedge Fund Research (HFR). ${ }^{16}$ We use these data to check whether the estimates of hedge fund factor exposures that we obtain using our method, based on only monthly returns, are similar to those that would be obtained if daily data were available. As the HFR daily returns are only available at the index level and begin only in April 2003, they are not a replacement for the comprehensive data that we

\footnotetext{
${ }^{15}$ The first-order autocorrelation of these variables ranges from 0.38 (USD/JPY RV) to 0.99 (VIX), while the largest first-order autocorrelation of the remaining 13 variables is only 0.18 . We estimate the optimal EWMA smoothing coefficient for each of these six series using non-linear least squares.

${ }^{16}$ To our knowledge, Distaso, et al. (2009) are the first to study the properties of these data.
} 
employ on individual hedge funds. Nevertheless this daily information provides us with valuable insights into the performance of our method.

We employ the daily HFR indices for five hedge fund styles: equity hedge, macro, directional, merger arbitrage, and relative value. ${ }^{17}$ The period April 2003 to June 2009 yields 1575 daily observations and 76 monthly observations. ${ }^{18}$ In our main empirical analysis in Section 5 below, we consider the seven-factor Fung-Hsieh model for hedge fund returns, but three of the Fung-Hsieh factors (the returns on three portfolios of lookback straddle options) are only available at a monthly frequency, and so they are not suitable for our model of daily hedge fund index returns. Thus we restrict our attention to the four Fung-Hsieh factors that are available at the daily frequency. As in our main analysis below, we follow Bollen and Whaley (2009) and reduce the Fung-Hsieh model to a more parsimonious two-factor specification by using the Bayesian Information Criterion to find the two Fung-Hsieh factors that best describe the daily hedge fund index returns. The chosen factors and the coefficients on these factors in models using daily and monthly returns are presented in Table II.

Table II reports the estimation results for the constant-beta factor model, using both daily and monthly hedge fund returns. This table confirms that estimating a constant-beta model using monthly returns data yields similar parameter estimates to those obtained using daily data. As expected, $t$-statistics are generally lower in the model estimated on monthly data, but the signs and magnitudes of the estimated parameters are generally close.

Table III presents the results of the model for time-varying factor exposures based on conditioning information, estimated either using daily returns or using monthly returns. The models

\footnotetext{
${ }^{17}$ In total there are nine HFR indices that are available for at least 24 months and have a clear strategy definition. The four remaining style indices generate results that are similar to one of the included style indices; specifically, the convertible arbitrage and distressed securities indices have similar results to the relative value index, market neutral has similar results to macro, and event driven is similar to directional. These results are omitted in the interests of brevity and are available on request.

${ }^{18}$ The HFR directional index started on 1 July 2004 and so slightly fewer observations are available for this series: 1259 daily observations and 60 monthly observations.
} 
that are estimated are the two-factor versions of the models presented in equations (7) and (9):

$$
\begin{aligned}
r_{i d}^{*}= & \alpha_{i}+\beta_{i 1} f_{1 d}^{*}+\beta_{i 2} f_{2 d}^{*}+\gamma_{i 1} f_{1 d}^{*} Z_{d-1}+\gamma_{i 2} f_{2 d}^{*} Z_{d-1} \\
& +\delta_{i 1} f_{1 d}^{*} Z_{d-1}^{*}+\delta_{i 2} f_{2 d}^{*} Z_{d-1}^{*}+\varepsilon_{i d}^{*} \\
r_{i t}= & n(t) \alpha_{i}+\beta_{i 1} f_{1 t}+\beta_{i 2} f_{2 t}+\gamma_{i 1} f_{1 t} Z_{t-1}+\gamma_{i 2} f_{2 t} Z_{t-1} \\
& +\delta_{i 1} \sum_{d \in \mathcal{M}(t)} f_{1 d}^{*} Z_{d-1}^{*}+\delta_{i 2} \sum_{d \in \mathcal{M}(t)} f_{2 d}^{*} Z_{d-1}^{*}+\varepsilon_{i t},
\end{aligned}
$$

where $\alpha_{i}$ is the daily alpha of the fund, $\beta_{i 1}$ and $\beta_{i 2}$ are the constant exposures to the two factors $f_{1}$ and $f_{2}, \gamma_{i 1}$ and $\gamma_{i 2}$ capture variations in factor exposures that occur at the monthly frequency (with the variable $Z_{t}$ ) and $\delta_{i 1}$ and $\delta_{i 2}$ capture variations in factor exposures that occur at the daily frequency (with the variable $Z_{d}^{*}$ ).

If the methodology presented in Section 2 is accurate, then we would expect to see similar parameter estimates across the two sampling frequencies. Up to sampling variability, this is indeed what we observe: Across all five indices, the signs of the estimated coefficients generally agree, and cases of disagreement all coincide with at least one parameter estimate that is not significantly different from zero. As expected, the parameter estimates obtained from monthly returns are generally less accurate than those estimated using daily returns. Further supporting our approach, the $p$-values from the bootstrap test for the significance of time-varying factor exposures agree in all but one case: for the equity hedge, directional, relative value indices significant variation is detected using both daily and monthly returns, for the macro index no significant variation is detected using either frequency, while for the merger arbitrage index significant variation is found using daily data but not monthly data. In this latter case, the lack of daily returns on the index hinders our ability to detect time-varying factor exposures.

Table III also presents the correlation between the time series of daily factor exposures (betas) estimated using daily and monthly returns. For example, the correlation between the time series of daily exposure to the S\&P500 of the equity hedge index estimated using daily and monthly returns is 0.89 , and the correlation of daily estimates of this index's exposure to BAAMTSY is 0.94. Similar positive results are found for the directional and merger arb indices. For the macro index both correlations are negative, however for that index no evidence of time-varying beta is found, using either daily or monthly returns (the bootstrap $p$-values from the tests were 0.72 and 0.69 respectively), and so the estimated daily betas are essentially just noisy estimates of a constant 
value, and as such we would not necessarily expect a positive correlation between daily and monthly estimates. For the relative value index we find a positive correlation between the daily and monthly estimates of beta on the S\&P 500 index, but a negative correlation for the beta on the BAAMTSY index. The explanation for the negative correlation can be seen from the estimated values of $\gamma_{2}$ and $\delta_{2}$ : using daily data these are estimated as positive and borderline significant, while using monthly data they are negative and not significant. In this case, the loss of precision from using monthly data may mean there are gains in practice from setting insignificant parameters to zero.

In Figures 1 and 2 we present an illustration of the correspondence between the estimates of daily factor exposures estimated using actual daily index returns, or using only monthly returns. For clarity, we narrow the focus of these plots to the last quarter of our sample period (April 2009 to June 2009), similar conclusions are drawn from other sub-periods. These figures illustrate the strong similarity between the two estimates of time-varying exposure to the S\&P500 index, and provide further support for the modelling approach proposed in Section 2.

\subsection{Results from a simulation study}

Next, we consider a simulation study designed to further investigate the accuracy of our proposed estimation method. For simplicity, we consider a one-factor model for a hypothetical hedge fund, and as in our main empirical analysis below, we allow factor exposures to vary at both the daily and monthly frequencies. We simplify the notation and assume that each month contains exactly 22 trading days. This yields a process for daily hedge fund returns as:

$$
r_{d}^{*}=\alpha+\beta f_{d}^{*}+\gamma f_{d}^{*} Z_{d-1}+\delta f_{d}^{*} Z_{d-1}^{*}+\varepsilon_{R, d}^{*}, \quad d=1,2, \ldots, 22 \times T,
$$

The parameter $\beta$ captures the average level of beta for this fund, $\gamma$ captures variations in beta that are attributable to the monthly variable $Z_{d}$, and $\delta$ captures variations in beta that are attributable to the daily variable $Z_{d}^{*}$. If we aggregate this process up to the monthly frequency we obtain:

$$
r_{t}=22 \alpha+\beta f_{t}+\gamma f_{t} Z_{t-1}+\delta \sum_{j=0}^{21} f_{22 t-j}^{*} Z_{22 t-j-1}^{*}+\varepsilon_{R, t}, \quad t=1,2, \ldots, T .
$$

where $r_{t} \equiv \sum_{j=0}^{21} r_{22 t-j}^{*}$, is the monthly equivalent of the daily variable in the above specification, and analogously for $f_{t}$ and $Z_{t}$. The parameters $\alpha, \beta$ and $\gamma$ are all estimable using only monthly data; the focus of this simulation study is our ability to estimate $\delta$, and whether attempting to do so adversely affects our estimates of the remaining parameters. 
We next specify the dynamics and distribution of the factor and the conditioning variable. To allow for autocorrelation in the conditioning variable (as found in such variables as volatility and turnover) we use an $\operatorname{AR}(1)$ process for $Z_{d}^{*}$ :

$$
Z_{d}^{*}=\phi_{Z} Z_{d-1}^{*}+\varepsilon_{Z, d}^{*}
$$

The conditioning variable is de-meaned prior to estimation, and so the omission of an intercept in the above specification is without loss of generality. We also assume an $A R(1)$ for the factor returns, to allow for the possibility that these are also autocorrelated:

$$
f_{d}^{*}=\mu_{F}+\phi_{F}\left(f_{d-1}^{*}-\mu_{F}\right)+\varepsilon_{F, d}^{*}
$$

Finally, we assume that all innovations are normally distributed, and we allow for correlation between the factor innovations and the innovations to the conditioning variable:

$$
\left[\varepsilon_{R, d}^{*}, \varepsilon_{F, d}^{*}, \varepsilon_{Z, d}^{*}\right]^{\prime} \sim N\left(\left[\begin{array}{c}
0 \\
0 \\
0
\end{array}\right],\left[\begin{array}{ccc}
\sigma_{\varepsilon R}^{2} & 0 & 0 \\
\cdot & \sigma_{\varepsilon F}^{2} & \rho_{F Z} \sigma_{\varepsilon F} \sigma_{\varepsilon Z} \\
\cdot & . & \sigma_{\varepsilon Z}^{2}
\end{array}\right]\right)
$$

To obtain realistic parameter values for the simulation we calibrate the model to the results obtained when estimating the model using daily HFR equity hedge index returns. This leads to the following parameters for our simulation:

$$
\begin{aligned}
\alpha & =2 /(22 \times 12), \beta=0.4, \gamma=0.002, \delta=-0.004 \\
\mu_{F} & =10 /(22 \times 12), \sigma_{F}=20 / \sqrt{22 \times 12}, \sigma_{Z}=10, \sigma_{\varepsilon R}=\sqrt{0.1}
\end{aligned}
$$

Thus we assume that the fund generates $2 \%$ alpha per annum with an average beta of 0.4 , and a daily beta that varies with both daily and monthly fluctuations in the conditioning variable $\left(Z^{*}\right.$ and $Z$ ). The factor is assumed to have an average return of $10 \%$ per annum and an annual standard deviation of $20 \%$. The conditioning variable has daily standard deviation of 10 (similar to the VIX), and the innovation to the returns process has a daily variance of 0.1 , which corresponds to an $R^{2}$ of around 0.6 in this design.

We vary the other parameters of the returns generating process in order to study the sensitivity 
of the method to these parameters. We consider:

$$
\begin{aligned}
\phi_{Z} & \in\{0,0.5,0.9\} \\
\phi_{F} & \in\{-0.2,0,0.2\} \\
\rho_{F Z} & \in\{0,0.5\} \\
T & \in\{24,60,120\}
\end{aligned}
$$

Thus, we allow the conditioning variable to vary from iid $\left(\phi_{Z}=0\right)$ to persistent $\left(\phi_{Z}=0.9\right)$; we allow for moderate negative or positive autocorrelation in the factor returns; we allow for zero or positive correlation between the factor and the conditioning variable; and we consider three sample sizes: 24 months, 60 months or 120 months, which covers the relevant range of sample sizes in our empirical analysis (the average sample size in our empirical application is 62 months). We simulate each configuration of parameters 1000 times, and report the results in Table IV.

The table shows that the estimation method proposed in Section 2 performs very well in all the scenarios that we consider. In the "base" scenario, we see that with just 60 months of data we are able to reasonably accurately estimate the parameters of this model, including the parameter $\delta$, which allows us to capture daily variation in hedge fund risk exposures. Across a range of different sample sizes, degrees of autocorrelation, and correlation with the factor return, we see that the estimation method performs well: The $90 \%$ confidence interval of the distribution of parameter estimates contains the true parameter in all ten scenarios that we consider.

Overall, our analysis of daily returns on hedge fund indices and the simulation results of this section provide strong support for the reliability of our estimation procedure in practice. Given daily data on conditioning variables, the results of this section confirm that our method provides a means of obtaining reliable estimates of daily risk exposures from monthly hedge fund returns.

\section{Empirical evidence on dynamic risk exposures}

Given the relatively short histories of returns for the hedge funds in our sample documented in Table I, and the data-intensive nature of the models for dynamic risk exposures to be estimated, controlling the number of parameters to be estimated is important. In view of this, we follow Bollen and Whaley (2009) and reduce the full seven-factor Fung-Hsieh model to a more parsimonious twofactor model. For each individual fund, we choose the two-variable subset of factors from the full 
set of seven that minimizes the Bayesian Information Criterion when the fund's returns are on the left-hand side. ${ }^{19}$ Figure 3 shows that the most frequently selected factor is the S\&P 500 index, chosen for $60.5 \%$ of the funds. Of the remaining six factors, the most frequently selected is the size factor (SMB) while the second most frequently selected factor is the default spread (BAAMTSY), which are chosen for $33.1 \%$ and $32.6 \%$ of funds respectively. Figure 4 breaks this down across the nine strategy groups and shows that the selected second factors are generally consistent with intuition about the factors on which different strategies load. For example, within the Global Macro strategy, the most frequently picked second factor is the return on a portfolio of lookback straddle options on currencies (PTFSFX), whereas for fixed income the default spread (BAAMTSY) is the most frequently picked. With these "optimal" two-factor models for each individual fund, we now turn to models for dynamic exposures to these factors.

\subsection{Optimal conditioning variables for dynamic risk exposures}

In Section 3.3 we discussed the complete set of 19 variables we consider as conditioning variables for capturing time variations in hedge funds' risk exposures. Although the model described in Section 2.3 extends naturally to handle both more risk factors, $f_{t}$, and more conditioning variables, $Z_{t}$, the limited time series of data we have on individual funds compels us to keep the model as simple as possible. To that end, we consider only a single conditioning variable in the model, which drives variation in both risk exposures. ${ }^{20}$ We search across the set of 19 conditioning variables to find the variable that is the most significant for a given fund, and to test the significance of the selected conditioning variable we control for the fact that it is the outcome of a specification search by using the "bootstrap reality check" approach of White (2000), described in Section 2.4.2. ${ }^{21}$

\footnotetext{
${ }^{19}$ As the number of parameters in each of these models is the same, minimizing the BIC is equivalent to maximizing the $R^{2}$ or adjusted $R^{2}$.

${ }^{20} \mathrm{It}$ is straightforward to extend our approach to allow for more than one conditioning variable or to allow for a different conditioning variable for each of the two factors. In the former case the main constraint is data and degrees of freedom, while in the latter case the only constraint is computation time.

${ }^{21}$ We measure the significance of a given conditioning variable by the $p$-value from a joint test that all coefficients on interaction terms involving that variable are zero. The number of parameter restrictions that this implies varies from two to four, depending on whether zero, one or two daily interaction terms are available for inclusion in the model. We use standard errors based on Newey and West (1987) to obtain the Wald test statistic and use the $\chi_{p}^{2}$ distribution, with $p=2$, 3, or 4 depending on the number of restrictions being tested, to obtain the $p$-value. The critical value for the $p$-value is determined using the reality check of White (2000).
} 
Table V presents the results of searching for the optimal conditioning variable for each of the 14,194 individual funds, and shows both the proportions of funds for which a given conditioning variable is selected, and the proportion of funds for which the selected conditioning variable is significant at the 0.10 level, according to the bootstrap reality check testing procedure. Table V orders the conditioning variables by the proportion of funds for which it was significant; the main difference between the two orderings is that lagged fund performance is selected frequently, but not significant as often.

Using the bootstrap testing procedure described in Section 2.4, we find that the best conditioning variable is significant for 3321 individual funds (23.4\% of the total number of funds), at the 0.10 level, substantially more than can be attributed purely to chance. The five most significant conditioning variables are $\triangle$ Level, the NASDAQ return, the USD/JPY Carry Trade Return, $\Delta$ Slope, and Fund Performance over the past 3 months. Clearly, funding and performance are the two most important drivers of changes in hedge funds' risk exposures. Interestingly, the liquidity measures Turnover and Amivest come in $16^{\text {th }}$ and $19^{\text {th }}$ respectively, suggesting that the other interaction variables in the model may already be capturing the role of liquidity in affecting time-variation in funds' exposures. While the frequency of selection is important, it is also of interest to consider the increase in the $R^{2}$ that obtains from augmenting the factor model with the conditioning variables. Across all funds, the $R^{2}$ increases from an average of $27.2 \%$ for the constant-parameter model to an average of $43.1 \%$ for the model with conditioning information. Next, we analyze whether this improvement in $R^{2}$ is attributable purely to the search process, or whether it reflects truly significant changes in hedge funds' risk exposures.

\subsection{Evidence of time-varying risk exposures}

Table VI presents the results of statistical tests for time-varying risk exposures, across the entire set of 14,194 individual hedge funds in our database. We present the proportion of funds for which we can reject the null of constant factor exposures at the 0.10 level, using the bootstrap testing approaches described in Section 2.4 .

The first column of Panel A of Table VI presents the results from a test based on the optimal changepoint model employed by Bollen and Whaley (2009), and the final row shows that, across all funds, we detect a significant changepoint for $21.4 \%$ of funds using the bootstrap test. Figure 5 shows the most frequently selected changepoint dates between January 1995 and July 2008. The 
three most frequently selected changepoint dates are February, June and July of 2008. The first date lies in a quarter in which significant financial volatility was witnessed in financial markets, while the second and third can be traced to the date of the G8 summit, which occurred in July 2008. However, if we look at the dates that are most often significant at the $10 \%$ level (shaded in dark in Figure 5) we find that May 2000, July 2008 and January 2001 and are the most significant changepoint dates. Both May 2000 and April 2001 are difficult to cleanly link to any well-known event in financial markets, although one might stretch the point and argue that May 2000 was two months post-NASDAQ-crash. The lack of significant events during several of the frequently selected changepoint months (and the relatively flat nature of the graph of significant break dates) highlights the difficulty in interpreting the results from the changepoint method, a relative advantage of our approach.

The second column of Panel A of Table VI presents the results from tests based on our proposed conditioning variable approach. As mentioned earlier, we find that 3321 funds, $(23.4 \%$ of the total) exhibit significant variation in factor exposures, a slightly higher proportion than the changepoint model. Interestingly, there is a low degree of overlap between these two sub-sets of funds: only $3.5 \%$ of funds exhibit both a significant changepoint and a significant conditioning variable. This limited overlap suggests a complementarity between the two modeling approaches: for some funds it appears that a change in beta is best modeled using a discrete one-time change, while for other funds it appears that beta varies more continuously.

Building on the above insight, in the third column of Panel A of Table VI we present the results of a "hybrid" model, where we first allow for a one-time change in beta using the optimal changepoint approach, and then conduct a search for the optimal conditioning variable. The results reveal that our method is even more useful once a changepoint has been identified: the proportion of funds for which there is a statistically significant conditioning variable rises to $30.1 \%$ of the full sample from the $23.4 \%$ originally detected. The proportion $30.1 \%$ may be interpreted as the significance of time-varying betas using our approach after allowing for time-varying betas following the approach of Bollen and Whaley (2009), and clearly reveals that our method offers additional gains in the modeling of time-varying hedge fund risk exposures.

Finally, Panel B of Table VI presents the results for all funds when we do not use a bootstrap procedure to account for the search across interactions or changepoints. The results here are clearly different: 80 to $90 \%$ of the funds appear to select time-varying models of factor exposures 
when we use the naive approach of testing whether the 'best' model (obtained after searching across changepoints or interactions) is preferred to a model with constant factor exposures. This highlights the importance of correctly accounting for the 'data mining' that goes into the search, a point emphasized in both the finance and statistics literatures (see Ferson and Schadt (1996), White (2000), Sullivan, Timmermann and White (1999), and Ferson, Sarkissian and Simin (2008)).

Table VI shows the percentage of funds selecting different models, but does not provide information about the magnitude of the improvements offered by our model on a fund-by-fund basis. Figure 6 depicts the performance of the models graphically for the entire set of 14, 194 funds in the data, plotting the cumulative distribution functions of the adjusted $R^{2}$ statistic for all funds for the different models (the plot is virtually the same with regular $R^{2}$ statistics), and summary statistics from these distributions is provided in Table VII. Confirming Bollen and Whaley's (2009) finding, Figure 6 shows that the changepoint model convincingly beats the constant-parameter models. This is not only true for the model estimated using the two-variable subset of the seven Fung-Hsieh factors selected in our first stage search procedure; it is also the case for the full seven-factor model. The latter is an attempt to model dynamic risk-exposures using an option-based replication of the returns from a posited dynamic trading strategy, and the graph confirms that this seems insufficient on its own to capture the movements in funds' risk exposures. Further, our model based on conditioning variables out-performs both the constant-parameter model and the changepoint model, in the sense that the CDF of our model everywhere lies under that of the constant model and the changepoint model. Finally, the hybrid model considered in column three of Table VI beats our model, confirming that there are gains to combining the changepoint and conditioning variable approaches. The mean and the median of the cross-sectional distribution of adjusted $R^{2}$ statistics shifts to the right by $6 \%$, when moving from the changepoint model to our interactions model.

In the final column of Table VI we seek to isolate the sources of the information from our modeling approach. In that column, we test for time-varying risk exposures using only monthly conditioning information. That is, we force the coefficients on the daily information to be zero, and use a pure Ferson-Schadt (1996) approach. The final row of that column reveals that we can reject constant risk exposures for $14.9 \%$ of funds, which is greater than the nominal size of the test $(10 \%)$ but substantially less than the proportion of $23.4 \%$ obtained when we use combine daily and monthly information. Furthermore, the overlap between these two tests is almost perfect $(14.2 \%)$, revealing that by including daily as well as monthly conditioning information we increase 
the number of funds for which we can detect time-varying risk exposures by 8.5\%, a total of 1,201 individual funds. This highlights an interesting and previously undocumented new feature of hedge funds: (some) hedge funds alter their exposures to standard risk factors at the daily frequency, in ways that can be detected using an econometric model at the monthly frequency.

\subsection{Time-varying risk exposures across hedge fund styles}

In addition to the overall proportions of funds for which significant variations in risk exposures are found, Table VI also breaks these down by hedge fund style. Doing so allows us greater insight into the heterogeneity, if present, across the set of 14,194 individual funds. From these we see that there are three styles for which the proposed conditioning information approach does particularly well compared with the optimal changepoint approach (relative value, funds of funds, and fixed income), four styles for which the two approaches do approximately equally well (security selection, directional traders, multi-process and emerging markets) and two styles where the changepoint approach dominates (macro and CTAs). It is noteworthy that the styles for which the interactions model out-performs the changepoint model are also those strategies for which the daily information substantially increases the percentage of funds with significant interaction variables. For example, for the fixed income and relative value styles we find that our approach identifies substantially more significant variations in risk exposures than the optimal changepoint approach, and for these two styles the gains over the model based on monthly conditioning information are also among the largest. For the macro and CTA styles, on the other hand, the changepoint approach out-performs the approach based on conditioning information, and for those styles there appears to be only small gains from using daily information.

To provide further insights into the differences across strategy groups, Table VIII lists the most often selected interaction variables across the strategy groups. Studies of the effect of leverage on hedge fund returns have been somewhat sparse given the lack of detailed data on this aspect of hedge funds' activities, and authors have adopted different strategies for ascertaining these effects. For example, using simulations, Khandani and Lo (2008) highlight that systematic portfolio deleveraging by long-short equity hedge funds could have been responsible for the "quant meltdown" of August 2007. Liang (1999) uses the self-reported data in the HFR database on hedge funds' use of leverage, and documents that while there is no discernible difference across all funds between those using leverage and those not using leverage, convertible arbitrage and merger arbitrage funds 
benefit from the use of leverage, while emerging market funds are hurt by the use of leverage. In keeping with this observation, Table VIII shows that for Relative Value (which contains merger arbitrage funds), all three of the most frequently picked interaction variables are from the leverage category.

Table VIII also reveals that the USD/JPY Carry Trade Return is the most frequently selected interaction variable for two strategies which are closely associated with trading in foreign exchange instruments, namely the Macro and Emerging Markets funds. In recent press reports, there has been a lot of attention paid to the use of the carry trade as a cheap source of funding for hedge funds, and this finding provides some evidence to support that this may be an important vehicle. ${ }^{22}$

The most frequently selected variables across all strategies are $\Delta$ Level, the NASDAQ return and the USD/JPY Carry Trade Return. Across our four categories of conditioning variables (liquidity, funding and leverage, volatility, and performance), variations in funding costs appear to be the main driver of the changes in factor loadings across all strategy groups, accounting for 17 of the 30 top three variables per strategy. These results confirm the significant role of leverage in hedge funds' return-generation processes.

\subsection{Time-varying risk exposures and performance measurement}

A straightforward way to test the efficient markets hypothesis is to inspect the portfolio returns of putatively sophisticated agents, such as mutual fund or hedge fund managers, to see if they earn more than a fair compensation for risk. Jensen's (1968) study was perhaps the first systematic analysis of this nature, which arrived at the pessimistic conclusion that gross of expenses, mutual funds achieved a negative average net-of-expenses alpha. Following a host of initial studies that broadly confirmed this proposition, Ferson and Schadt (1996) first used the time-varying exposure method to shed light on this question. They motivated their analysis by using the example of a hypothetical manager who wishes to keep fund volatility stable over time in an economy in which expected excess market returns and market volatility jointly co-vary with economic conditions. Their insight is that unconditional performance evaluation of this manager will yield negative alpha estimates if the time-variation in fund risk exposures is not properly accounted for. Using their method, they overturn the conclusion that the alpha of the mutual funds in their sample is

\footnotetext{
${ }^{22}$ See: "Hedge funds' ATM moves from Tokyo to Washington," Bloomberg, September 19, 2009, and "Fears rise for dollar carry trade future," Financial Times, February 23, 2010.
} 
negative; their conditional performance evaluation reveals that the performance of these funds over the 1968 to 1990 period is broadly neutral.

Table IX, Panel A shows how the use of our time-varying exposure model affects inferences about hedge-fund alpha. The table contrasts the alphas obtained from a static factor model (using the optimally selected two factors from the set of all seven) with those obtained from our timevarying exposure model. Across all funds, the average alpha from the two models looks virtually identical, at around $8 \%$ per annum for both models ${ }^{23}$. When we restrict the sample of funds to those which reject the null of constant factor exposures, however, the alpha of these funds obtained from the time-varying exposure model are significantly higher (by approximately half a percent per annum) than those from the static factor model. This conclusion is similar to that of Ferson and Schadt (1996), and suggests that on average, hedge funds' variations in risk-exposures are broadly (although mildly) beneficial to investors. This conclusion is quite relevant when considering that the baseline constant alpha for this sub-sample of funds is lower than the overall average, at $6.5 \%$ per annum.

Simply analyzing the average difference of the alphas misses an important point, namely that the performance of some funds may improve and the performance of others may decline when the time-varying exposures model is applied. To account for this we first separately estimated these average differences in alpha estimates for each strategy for the funds with significant time-variation. These results are presented in Panel B of Table IX, and they reveal interesting heterogeneity in the estimates. For example, the 84 Emerging Markets funds with significantly time-varying risk exposures have $4.8 \%$ per annum lower alphas under the interactions model than under the constant factor model, whereas for the 35 relative value funds, alphas are on average $1.9 \%$ per annum higher under the interactions model. Second, to see if there are differences between the two models' inferences on any given fund, we measured the average of the absolute value of the difference between the alphas from the two models. Table IX, Panel A shows that across all funds, we find a large and highly statistically significant difference of $3.2 \%$ per annum (around $40 \%$ of the average alpha) between the alphas from the two models. Again, when we estimate this difference for only the funds which reject the null of constant factor exposures, we find that it increases to a

\footnotetext{
${ }^{23}$ We use raw hedge fund returns (net of fees) for the analysis in this paper. The average annualized risk free rate over our sample period is $3.6 \%$, and subtracting that from our estimates in Table IX yields average alphas that are comparable to previous studies.
} 
statistically significant $4.6 \%$.

Finally, we checked the similarity of the performance rankings generated by the two models. Table IX, Panel A shows that while the correlations of these rankings are high across all funds (the rank correlation of alphas is $86 \%$ ), for the subset of funds with significant time-variation in exposures, there are bigger shifts. In particular, the rank correlation between the two sets of alpha measures for this cross-section drops to $74 \%$, suggesting that there are important differences in the relative performance evaluation of these hedge funds generated by the use of the time-varying risk-exposure model.

\section{Robustness Checks}

Table X presents robustness checks used to identify whether the method proposed in this paper performs well over different sample periods, over different samples of funds, and under different transformations of hedge fund returns. The first robustness check that we run is to split the sample period into two halves, with the second half beginning in 2002, after the NASDAQ crash, and extending up to 2009, including the credit crisis period. We find that the changepoint approach performs better over the earlier period, with $22.6 \%$ of the funds rejecting the null of no break in risk exposures, whereas our method performs relatively less well, with $17.4 \%$ of funds rejecting the null of no significant interaction variables. In the second sub-period, the relative performance is reversed, with only $14 \%$ of the funds selecting changepoints, and almost $30 \%$ of the funds selecting interactions. This might be explained by the population of funds shifting towards funds with fastermoving trading strategies, which would suggest that our method is more appropriate to use in the contemporary setting.

Next, we investigate our use of the Getmansky, Lo and Makarov (2004) unsmoothing of hedge

fund returns. When we do not apply this transformation to the returns data, both the changepoint and interaction approaches perform better. This may be because the lower volatility of unsmoothed returns makes it relatively easier to detect variations in risk exposures. However, this result should be viewed with caution, since the timing of the changepoint detected from raw (smoothed) returns may be erroneous given that these returns reflect the performance of past and not just contemporaneous trading strategies in any given period. Using a longer number of lags (4 rather than 2) when estimating the moving average model barely affects the performance of either model. 
We then condition on the length of available return history for the funds, and find that the interaction-based method performs better for funds with shorter history lengths, while the changepoint approach performs best for funds with longer return histories. This results suggests that changepoint regressions may be better at detecting longer-lived and discrete movements in trading strategies, whereas our method may be better at picking up more rapid changes in funds' trading. It may also be a sign that our choice of only one interaction variable per fund over its entire lifetime may be somewhat restrictive, and that allowing for multiple interaction variables to be selected at different stages of a fund's life may improve the performance of our method.

Finally, we condition on the size of the fund. We find that our method works best for the largest funds in our sample (measured by the average AUM over the fund's lifetime), while the changepoint approach works best for the medium-sized funds. Overall, the robustness checks reveal that the two methods have complementary strengths, and are seemingly better equipped to capture variation in risk exposures for different types of funds. Put differently, these robustness checks further strengthen our earlier finding that the hybrid model of changepoints and interactions may do best of all at capturing hedge funds' time-varying risk exposures.

\section{Conclusion}

Recent research on hedge funds and mutual funds has documented the importance of accounting for the dynamic nature of the risk exposures of these actively managed investment vehicles. Several approaches have been proposed in the literature, including modelling these risk exposures as unobserved latent factors, and employing optimal changepoint regression techniques. We add to this literature with a new model that is related to the well-known Ferson and Schadt (1996) conditional performance evaluation model, extending this approach to capture the daily variation in hedge funds' factor exposures through the use of daily conditioning variables.

Using a comprehensive database of nearly 15,000 individual hedge funds over the 1994 to 2009 period, we find that our model performs well on statistical grounds, beating the constant parameter model, and also out-performing more sophisticated models such as the changepoint regression approach. The extension of our model to capture daily variation in factor exposures is important

in this context: A model with purely monthly interaction variables performs worse, in terms of the number of funds for which significant variations in risk exposures is detected, than the changepoint 
regression approach, and the addition of daily information to the monthly conditioning information allows us to identify over 1,000 more funds with time-varying betas. In addition to its good statistical performance, our approach provides the added benefit of economic interpretability of the changes in factor exposures. We find that variations in the cost of leverage, the performance of the carry trade, and the performance of commonly employed benchmarks such as the NASDAQ are important drivers of hedge funds' risk exposures. These findings add to the sparse evidence on the role of leverage in hedge funds' risk profiles, an area of increasing importance in light of recent public debates. 


\section{Appendix A: The Consolidated Hedge Fund Database}

As hedge funds can report to one or more databases, the use of any single source will fail to capture the complete universe of hedge fund data. We therefore aggregate data from TASS, HFR, CISDM, BarclayHedge and Morningstar, which together have 48,508 records that comprise administrative information as well as returns and AUM data for hedge funds, fund of funds and CTAs. However this number hides the fact that there is significant duplication of information, as multiple providers often cover the same fund. To identify all unique entities, we must therefore consolidate the aggregated data.

To do so, we adopt the following steps:

1. Group the Data: Records are grouped based on reported management company names. To do so, we first create a 'Fund name key' and a 'Management company key' for each data record, by parsing the original fund name and management company name for punctuations, filler words (e.g., 'Fund', 'Class'), and spelling errors. We then combine the fund and management name keys into 4,409 management company groups.

2. De-Duplication: Within a management company group, records are compared based on returns data (converted into US dollars), and 18,130 match sets are created out of matching records, allowing for a small error tolerance limit (10\% deviation) to allow for data reporting errors.

3. Selection: Once all matches within all management company groups are identified, a single record representing the unique underlying fund is created for each match set. We pick the record with the longest returns data history available is selected from the match set, and fill in any missing administrative information using the remaining records in the match set. The process thus yields 18,130 representative fund records.

Finally, we apply the criterion that 24 contiguous months of return data are available for each of the funds in the sample we use in the paper. This brings the final number of funds in the sample to 14,194 . 


\section{Table A.1: Data Sources}

This table shows the number of funds from each of the five sources (HFR, TASS, CISDM, MSCI and BarclayHedge), and the number of these funds that are alive and defunct (either liquidated or closed) in the consolidated universe of hedge fund data.

\begin{tabular}{lcccc}
\hline Source Dataset & Number of Funds & Alive & Defunct & $\%$ Defunct \\
\hline TASS & 5962 & 2738 & 3224 & 54.076 \\
HFR & 3712 & 2449 & 1263 & 34.025 \\
CISDM & 2782 & 860 & 1922 & 69.087 \\
BarclayHedge & 966 & 930 & 36 & 3.727 \\
Morningstar & 772 & 681 & 91 & 11.788 \\
Total & 14194 & 7658 & 6536 & 46.048 \\
\hline
\end{tabular}




\section{References}

[1] Ackermann, C., R. McEnally and D. Ravenscraft, 1999, The Performance of hedge funds: Risk, return and incentives, Journal of Finance 54, 833-874.

[2] Admati, A., S. Bhattacharya, P. Pfleiderer and S. Ross, 1986, On Timing and Selectivity. Journal of Finance, 715-732.

[3] Agarwal, V. and N. Y. Naik, 2004, Risks and Portfolio Decisions Involving Hedge Funds, Review of Financial Studies, 17(1), 63-98.

[4] Agarwal, V., N. Daniel and N. Y. Naik, 2009, Role of managerial incentives and discretion in hedge fund performance, Journal of Finance, 64(5), 2221-2256.

[5] Agarwal, V., W. Fung, Y. Loon and N. Y. Naik, 2009, Risk and Return in Convertible Arbitrage: Evidence from the Convertible Bond Market, Unpublished working paper.

[6] Amihud, Y., Mendelson, H. and Lauterbach, B., 1997. Market microstructure and securities values: evidence from the Tel Aviv exchange. Journal of Financial Economics 45, pp. 365-390..

[7] Amihud, Y., 2002, Illiquidity and stock returns: cross-section and time-series effects, Journal of Financial Markets 5, 31-56.

[8] Andrews, D.W.K., I. Lee and W. Ploberger, 1996, Optimal Changepoint Tests for Normal Linear Regression, Journal of Econometrics, 70, 9-38.

[9] Aragon, G., 2005, Share restrictions and asset pricing: Evidence from the hedge fund industry, Journal of Financial Economics 83, 33-58.

[10] Bollen, N.P.B. and J.A. Busse, 2001, On the Timing Ability of Mutual Fund Managers, Journal of Finance, 56, 1075-1094.

[11] Bollen, N.P.B. and R.E. Whaley, 2009, Hedge Fund Risk Dynamics: Implications for Performance Appraisal, Journal of Finance, 64(2), 985-1035.

[12] Busse, J., 1999, Volatility Timing in Mutual Funds: Evidence from Daily Returns, Review of Financial Studies 12, 1009-1041.

[13] Cao, C., Y. Chen and B. Liang, 2009, Can Hedge Funds Time Market Liquidity?, working paper, University of Massachusetts at Amherst.

[14] Chance, D. and M. Hemler, 2001, The Performance of Professional Market Timers: Daily Evidence from Executed Strategies, Journal of Financial Economics, 62, 377-411.

[15] Chen, H.-L., N. Jegadeesh and R. Wermers, 2000, The value of active mutual fund management: An examination of the stockholdings and trades of fund managers, Journal of Financial and Quantitative Analysis, 35, 343-368.

[16] Chen, Y. and B. Liang, 2007, Do Market Timing Hedge Funds Time the Markets?, Journal of Financial and Quantitative Analysis, 42, 827-856. 
[17] Chen, Z. and P. Knez, 1996, Portfolio Performance Measurement: Theory and Applications. Review of Financial Studies, 9, 511-555.

[18] Christopherson, J.A., W. Ferson and D. Glassman, 1998, Conditioning Manager Alpha on Economic Information: Another Look at the Persistence of Performance, Review of Financial Studies, 11, 111-142.

[19] Da, Z., P. Gao and R. Jagannathan, 2009, When Does A Mutual Fund's Trade Reveal Its Skill? working paper, Northwestern University.

[20] Daniel, K., M. Grinblatt, S. Titman, and R. Wermers, 1997, Measuring mutual fund performance with characteristic-based benchmarks. Journal of Finance 52, 1035-1058.

[21] Distaso, W., M. Fernandes and F. Zikes, 2009, Tailing Tail Risk in the Hedge Fund Industry, working paper, Imperial College London.

[22] Evans, M.D.D., 1994, Expected returns, time-varying risk and risk premia, Journal of Finance, 49, 655-680.

[23] Ferson, W.E., T. Henry and D. Kisgen, 2006, Evaluating Government Bond Fund Performance with Stochastic Discount Factors, Review of Financial Studies 19, 423-456.

[24] Ferson, W.E. and K. Khang, 2002, Conditional Performance Measurement Using Portfolio Weights: Evidence for Pension Funds, Journal of Financial Economics 65, 249-282.

[25] Ferson, W.E., S. Sarkissian and T. Simin, 2008, Asset Pricing Models with Conditional Alphas and Betas: The Effects of Data Snooping and Spurious Regression, Journal of Financial and Quantitative Analysis 43, 331-354.

[26] Ferson, W.E. and R.W. Schadt, 1996, Measuring Fund Strategy and Performance in Changing Economic Conditions, Journal of Finance, 51, 425-461.

[27] Fung, W., and D.A. Hsieh, 1997, Empirical characteristics of dynamic trading strategies: the case of hedge funds, Review of Financial Studies 10, 275-302.

[28] Fung, W., and D.A. Hsieh, 2001, The risk in hedge fund strategies: theory and evidence from trend followers, Review of Financial Studies 14, 313-341.

[29] Fung, W., and D.A. Hsieh, 2004a, Hedge fund benchmarks: A risk based approach, Financial Analysts Journal 60, 65-80.

[30] Fung, W., and D.A. Hsieh, 2004b, Asset-Based Style Factors for Hedge Funds, Financial Analysts Journal, 60, 65-80.

[31] Fung, W., D.A. Hsieh, N.Y. Naik and T. Ramadorai, 2008, Hedge funds: Performance, Risk and Capital Formation, Journal of Finance, 63(4), 1777-1803.

[32] Garleanu, N. and L.H. Pedersen, 2009, Margin-Based Asset Pricing and Deviations from the Law of One Price, Unpublished working paper.

[33] Getmansky, M., 2004, The Life Cycle of Hedge Funds: Fund Flows, Size and Performance, Unpublished working paper. 
[34] Getmansky, M., A.W. Lo and I. Makarov, 2004, An econometric model of serial correlation and illiquidity in hedge fund returns, Journal of Financial Economics 74, 529-610.

[35] Goetzmann W.N., Ingersoll J.E. and Z. Ivkovic, 2000, Monthly Measurement of Daily Timers, Journal of Financial and Quantitative Analysis, 35(3) pp.257-290.

[36] Goetzmann W.N., Ingersoll J.E. and Ross S.A., 2003, High-Water Marks and Hedge Fund Management Contracts, Journal of Finance, 58(4), 1685-1718.

[37] Graham, J., and C.R. Harvey, 1996, Market timing ability and volatility implied in investment newsletters' asset allocation recommendations. Journal of Financial Economics 42, 397-422.

[38] Griffin, J., F. Nardari and R. Stulz, 2007, Do investors trade more when stocks have performed well? Evidence from 46 countries, Review of Financial Studies, 20, 905-951.

[39] Hasbrouck, J., 2009, Trading Costs and Returns for US Equities: Estimating Effective Costs from Daily Data, Journal of Finance, forthcoming.

[40] Heber, G., A. Lunde, N. Shephard and K. Sheppard, 2009, Oxford-Man Institute's Realized Library, Version 0.1, Oxford-Man Institute, University of Oxford.

[41] Henriksson, R. and R. Merton, 1981, On Market Timing and Investment Performance. II. Statistical procedures for Evaluating Forecasting Skills. Journal of Business, 54, 513-533.

[42] Jagannathan, R., A. Malakhov and D. Novikov, 2010, Do hot hands exist among hedge fund managers? An empirical evaluation, Journal of Finance, 65(1), 217-255.

[43] Jagannathan, R. and Z. Wang, 1996, The Conditional CAPM and the Cross-Section of Expected Returns, Journal of Finance, 51, 3-54.

[44] Jensen, M., 1968, The Performance of Mutual Funds in the period 1945-1964, Journal of Finance, 23(2), 389-416.

[45] Khandani, A. and A. Lo, 2008, What Happened to the Quants in August 2007: Evidence from Factors and Transactions Data, Unpublished Working Paper.

[46] Kosowski, R., N.Y. Naik and M. Teo, 2007, Do hedge funds deliver alpha? A Bayesian and bootstrap analysis, Journal of Financial Economics, 84, 229-264.

[47] Lehmann, B. and D. Modest, 1987, Mutual Fund Performance Evaluation: A Comparison of Benchmarks and Benchmark Comparisons. Journal of Finance, 42, 233-265.

[48] Liang, B., 1999, On the Performance of Hedge Funds, Financial Analysts Journal, Summer edition, $72-85$.

[49] Mamaysky, H., M. Spiegel and H. Zhang, 2008, Estimating the Dynamics of Mutual Fund Alphas and Betas, Review of Financial Studies, 21, 233-264.

[50] Newey, W.K. and K.D. West, 1987, A Simple, Positive Semidefinite, Heteroskedasticity and Autocorrelation Consistent Covariance Matrix, Econometrica, 55, 703-708. 
[51] Panageas, S. and M. Westerfield, 2009, High-Water Marks: High Risk Appetites? Convex Compensation, Long Horizons, and Portfolio Choice, Journal of Finance, 64(1), 1-36.

[52] Patton, A.J., 2009, Are "Market Neutral" Hedge Funds Really Market Neutral?, Review of Financial Studies, 22(7), 2495-2530.

[53] Pollet, J. and M.I. Wilson, 2008, How Does Size Affect Mutual Fund Behavior? Journal of Finance, 63(6), 2941-2969.

[54] Politis, D.N. and J.P. Romano, 1994, The Stationary Bootstrap, Journal of the American Statistical Association, 89, 1303-1313.

[55] Ramadorai, T., 2009, The Secondary Market for Hedge Funds and the Closed-Hedge Fund Premium, Unpublished working paper.

[56] Rubin, R., A. Greenspan, J.A. Levitt and B. Born, 1999, Hedge Funds, Leverage, and the Lessons of Long-Term Capital Management, Report of the President's Working Group on Financial Markets

[57] Sadka, R., 2009, Liquidity Risk and the Cross-Section of Expected Hedge Fund Returns, Unpublished working paper.

[58] Sullivan, R., A. Timmermann and H. White, 1999, Data-Snooping, Technical Trading Rule Performance, and the Bootstrap, Journal of Finance, 54, 1647-1692.

[59] Teo, M., 2009, Geography of Hedge Funds, Review of Financial Studies, 22, 3531-3561.

[60] Teo, M., 2010, Hedge fund capacity constraints, liquidity, and hierarchy costs, Unpublished working paper.

[61] Todorov, V., 2009, Variance Risk Premium Dynamics: The Role of Jumps, Review of Financial Studies, 23(1), 345-383.

[62] Treynor, J. and K. Mazuy, 1966, Can Mutual Funds Outguess the Market? Harvard Business Review, 44, 131-136.

[63] Whaley, R.E., 2000, The investor fear gauge, Journal of Portfolio Management 26, 12-17.

[64] White, H., 2000, A Reality Check for Data Snooping, Econometrica, 68, 1097-1126. 


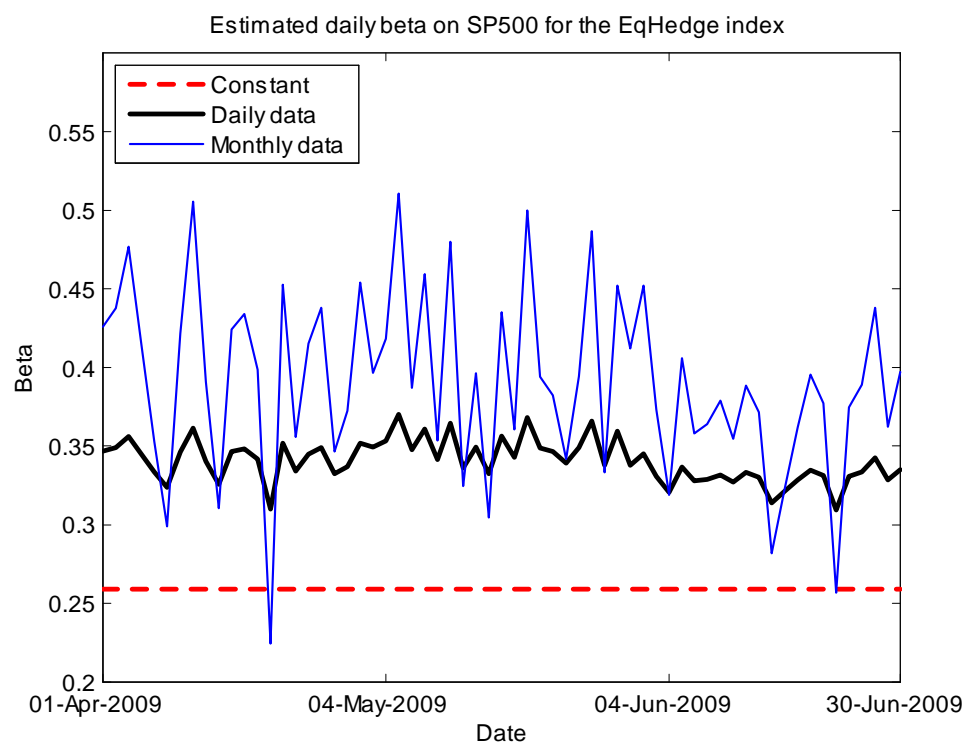

Figure 1: Estimates of the daily exposure of the HFR equity hedge index to the SP500 index over the second quarter of 2009 from three models: constant beta, time-varying beta using daily returns on the index, and time-varying beta using the proposed method based only on monthly returns.

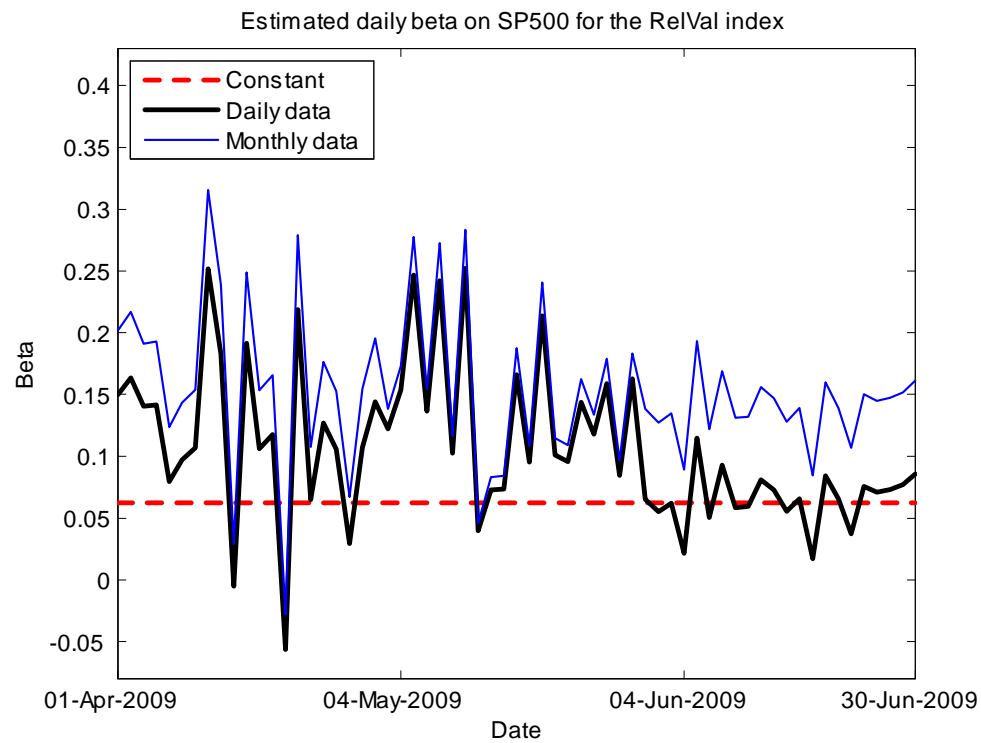

Figure 2: Estimates of the daily exposure of the HFR relative value index to the SESP 500 index over the second quarter of 2009 from three models: constant beta, time-varying beta using daily returns on the index, and time-varying beta using the proposed method based only on monthly returns. 


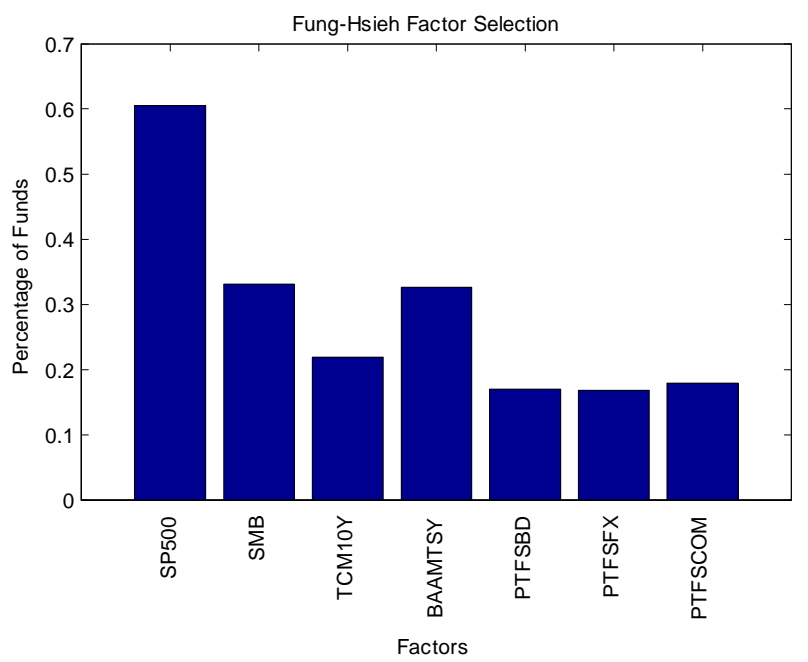

Figure 3: Proportion of times each of the Fung-Hsieh (2004) factors are selected in a two-factor model, as a percentage of the 14,194 individual funds.
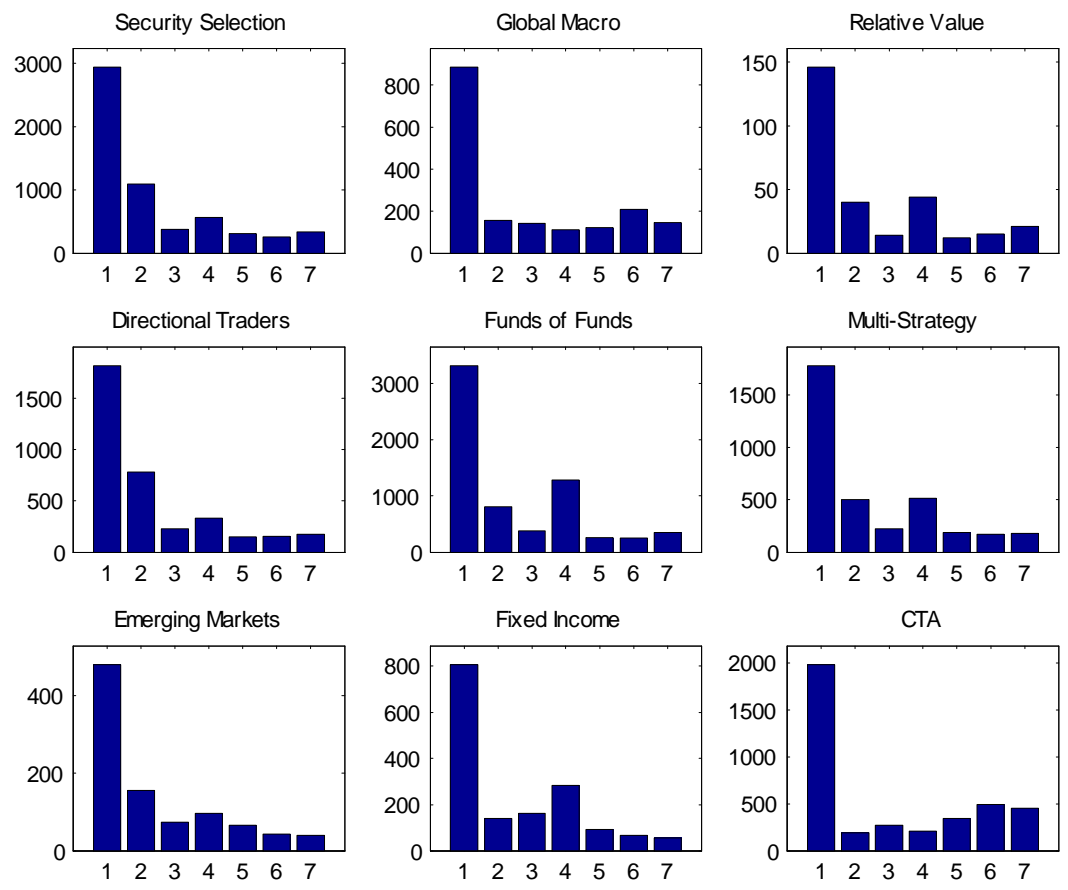

Figure 4: Number of times each of the Fung-Hsieh (2004) factors are selected in a two-factor model, for each of the nine hedge fund strategies. Factors 1-7 are, in order, SP500, SMB, TCM10Y, BAAMTSY, PTFSBD, PTFSFX, PTFSCOM. 


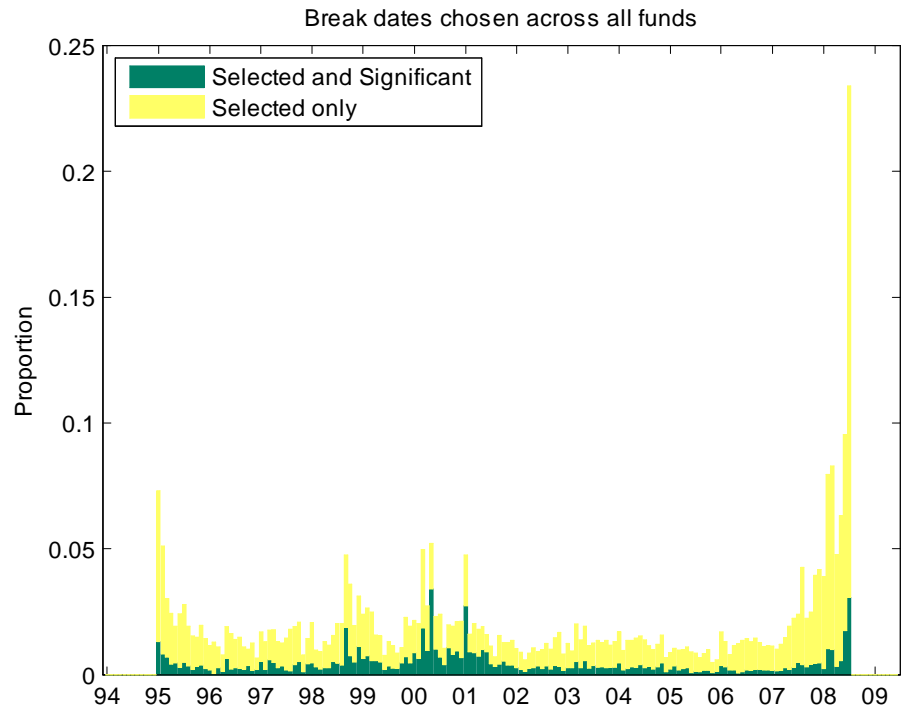

Figure 5: The number of funds which select a given date as a changepoint date, as a proportion of the all funds alive at that date, and the corresponding proportion of funds for which a given date is statistically significant.

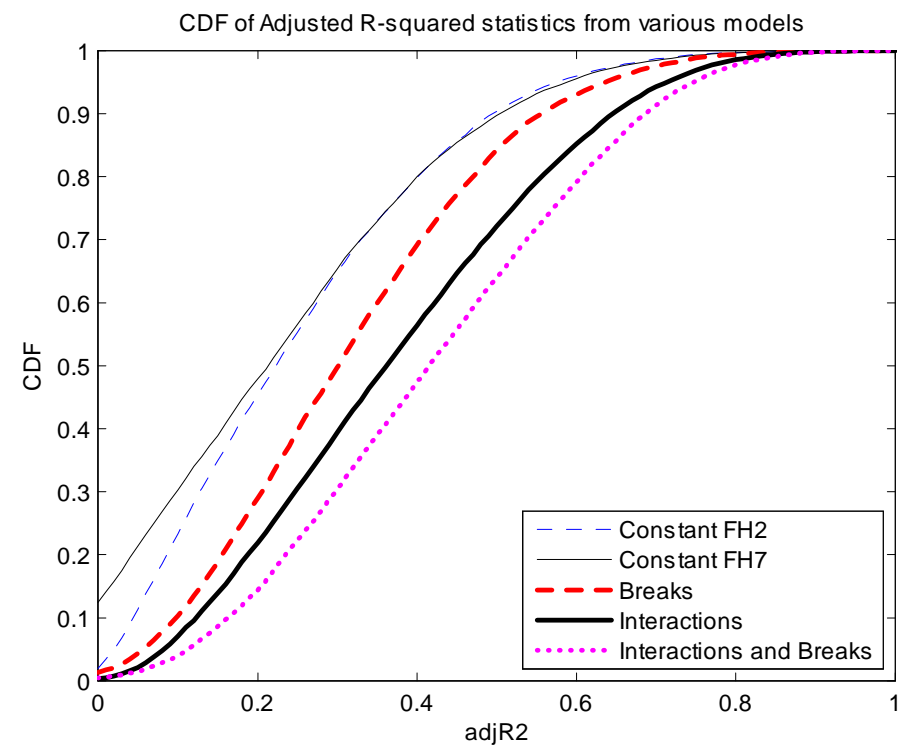

Figure 6: Empirical cumulative distribution function (CDF) of adjusted $R^{2}$ statistics from the constant-parameter model using all seven factors, constant-parameter model using only two optimally chosen factors, optimal changepoint (or "break") model, model with conditioning information ("interactions") or a combination of both models, across 14,194 individual funds. 
Table I

\section{Summary Statistics}

This table shows summary statistics for the funds in our sample. Panel A reports the percentiles of the pooled (cross-sectional) distribution of returns, unsmoothed returns, AUM, management fees, incentive fees, lockup and redemption notice periods. Panel B shows the percentages of funds in the consolidated sample of 14,194 which have return histories of the lengths specified in the column headers. Panel C shows the number and percentage of the 14,194 funds in each of the strategies represented in the rows.

Panel A

\begin{tabular}{lccccccc}
\hline & Returns & $\begin{array}{c}\text { Unsmoothed } \\
\text { Returns }\end{array}$ & $\begin{array}{c}\text { AUM } \\
(\$ M M)\end{array}$ & $\begin{array}{c}\text { Management } \\
\text { Fee }\end{array}$ & $\begin{array}{c}\text { Incentive Fee } \\
\text { Fee }\end{array}$ & $\begin{array}{c}\text { Lockup } \\
\text { (Days) }\end{array}$ & $\begin{array}{c}\text { Redemption Notice } \\
\text { (Days) }\end{array}$ \\
\hline 25th Prctile & -0.700 & -0.841 & 9.400 & 1.000 & 10.000 & 0.000 & 10.000 \\
50th Prctile & 0.720 & 0.710 & 32.000 & 1.500 & 20.000 & 0.000 & 30.000 \\
75th Prctile & 2.230 & 2.363 & 106.756 & 2.000 & 20.000 & 90.000 & 45.000 \\
Mean & 0.845 & 0.847 & 166.714 & 1.484 & 15.162 & 94.176 & 33.913
\end{tabular}

Panel B

\begin{tabular}{lccc}
\hline & $<36$ Months & $>=36,<60$ & $>=60$ \\
\hline Length(Return History) & 17.423 & 31.062 & 51.515
\end{tabular}

Panel C

\begin{tabular}{lcc}
\hline & \multicolumn{2}{c}{ Funds in Strategy } \\
\cline { 2 - 3 } & Percent & Number \\
\hline Security Selection & 20.752 & 2946 \\
Global Macro & 6.243 & 846 \\
Relative Value & 1.030 & 146 \\
Directional Traders & 12.788 & 1815 \\
Funds of Funds & 23.341 & 3313 \\
Multi-Process & 12.520 & 1777 \\
Emerging Markets & 3.372 & 479 \\
Fixed Income & 5.678 & 806 \\
CTAs & 13.973 & 1983 \\
Other & 0.303 & 43 \\
\hline TOTAL & 100 & 14194 \\
\hline
\end{tabular}




\section{Table II}

\section{Static Factor Models for Daily and Monthly Hedge Fund Style Indexes}

Table II shows results from a simple two-factor model applied to five hedge fund style index returns, identified in the first row of the table. In all cases a constant is included, and two factors from the set of four daily Fung-Hsieh factors are selected using the Bayesian Information Criterion. The first row presents annualized alpha. Robust t-statistics are reported below the parameter estimates, and the R2 and adjusted R2 are reported in the bottom two rows of the table.

\begin{tabular}{lcccccccccc}
\hline & \multicolumn{2}{c}{ Equity Hedge } & \multicolumn{2}{c}{ Macro } & \multicolumn{2}{c}{ Directional } & \multicolumn{2}{c}{ Merger Arbitrage } & \multicolumn{2}{c}{ Relative Value } \\
& Daily & Monthly & Daily & Monthly & Daily & Monthly & Daily & Monthly & Daily & Monthly \\
\hline Alpha & 1.575 & 1.595 & 3.738 & 3.322 & 3.044 & 3.709 & 5.444 & 5.331 & -1.032 & -0.473 \\
t-stat & 0.781 & 0.880 & 0.985 & 0.985 & 0.995 & 1.453 & 3.376 & 4.208 & -0.422 & -0.234 \\
SP500 & 0.259 & 0.321 & & & 0.270 & 0.327 & 0.111 & 0.063 & 0.063 & 0.190 \\
t-stat & 15.395 & 6.070 & & & 11.298 & 4.029 & 5.181 & 2.332 & 1.811 & 3.935 \\
SMB & & & 0.070 & 0.111 & & & & & & \\
t-stat & & & 2.111 & 0.849 & & & & & & \\
TCM10Y & & & -0.905 & -0.376 & & & & & & \\
t-stat & & & -2.742 & -0.405 & & & & & & \\
BAAMTSY & -2.006 & -2.027 & & & -2.720 & -3.861 & -0.460 & -0.579 & -2.544 & -6.080 \\
t-stat & -4.184 & -2.728 & & & -3.847 & -3.686 & -0.804 & -1.935 & -3.724 & -9.584 \\
\hline R2 & 0.549 & 0.681 & 0.014 & 0.007 & 0.454 & 0.664 & 0.290 & 0.182 & 0.090 & 0.784 \\
R2adj & 0.548 & 0.672 & 0.013 & -0.021 & 0.453 & 0.652 & 0.289 & 0.160 & 0.089 & 0.778 \\
\hline
\end{tabular}


Table III

Time-Varying Exposure Factor Models for Daily and Monthly Hedge Fund Style Indexes

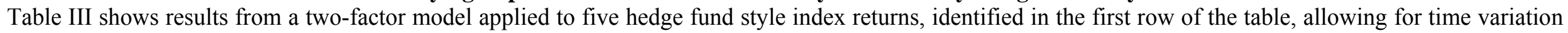

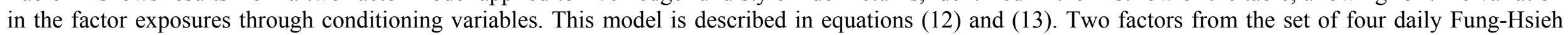
factors are selected using the Bayesian Information Criterion, and are identified in Table II. The first row presents annualized alpha. Robust t-statistics are

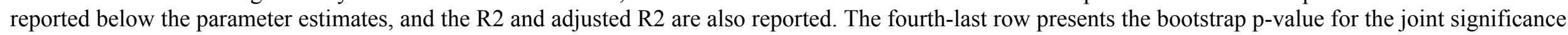
of the coefficients on the interaction terms (Gamma1, Gamma2, Delta1, Delta2), controlling for the search across possible interaction variables that was

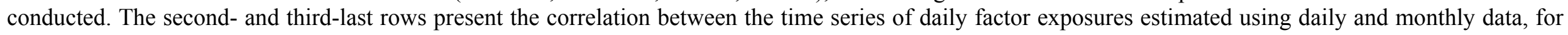
each of the two factors. The selected conditioning variable is presented in the final row.

\begin{tabular}{|c|c|c|c|c|c|c|c|c|c|c|}
\hline & \multicolumn{2}{|c|}{ Equity Hedge } & \multicolumn{2}{|c|}{ Macro } & \multicolumn{2}{|c|}{ Directional } & \multicolumn{2}{|c|}{ Merger Arbitrage } & \multicolumn{2}{|c|}{ Relative Value } \\
\hline & Daily & Monthly & Daily & Monthly & Daily & Monthly & Daily & Monthly & Daily & Monthly \\
\hline Alpha & 1.397 & 3.106 & 3.803 & 2.314 & 3.702 & 5.068 & 5.337 & 5.444 & -0.665 & 0.168 \\
\hline t-stat & 0.643 & 1.508 & 1.005 & 0.593 & 1.113 & 1.613 & 3.479 & 4.149 & -0.249 & 0.094 \\
\hline Beta1 & 0.301 & 0.321 & 0.064 & 0.090 & 0.264 & 0.357 & 0.116 & 0.071 & 0.067 & 0.144 \\
\hline t-stat & 38.426 & 6.374 & 2.520 & 0.586 & 29.344 & 3.940 & 25.547 & 1.954 & 8.465 & 2.927 \\
\hline Beta 2 & -1.832 & -1.829 & -0.859 & -0.651 & -2.590 & -1.920 & -0.388 & -0.619 & -2.293 & -6.144 \\
\hline t-stat & -6.417 & -2.613 & -3.685 & -0.554 & -6.789 & -1.468 & -2.137 & -1.064 & -7.252 & -7.795 \\
\hline Gamma1 & 0.006 & 0.009 & 0.037 & -0.509 & 0.086 & 0.272 & 0.011 & 0.004 & 0.016 & 0.003 \\
\hline t-stat & 8.053 & 1.526 & 0.993 & -1.349 & 7.839 & 2.395 & 9.685 & 0.578 & 7.969 & 0.304 \\
\hline Gamma2 & -0.007 & 0.025 & 0.886 & -1.306 & -0.352 & 1.209 & 0.098 & 0.108 & 0.174 & -0.140 \\
\hline t-stat & -0.228 & 0.223 & 2.207 & -0.534 & -0.759 & 0.641 & 2.002 & 0.832 & 2.040 & -0.800 \\
\hline Delta1 & 0.006 & 0.034 & -0.456 & -0.020 & 0.053 & -0.164 & -0.005 & 0.001 & 0.048 & 0.053 \\
\hline t-stat & 2.682 & 2.848 & -1.985 & -0.009 & 0.878 & -0.570 & -1.218 & 0.064 & 7.236 & 1.884 \\
\hline Delta2 & 0.216 & 0.340 & 10.538 & -21.165 & -14.831 & -42.915 & -0.233 & -2.386 & 0.498 & -2.631 \\
\hline t-stat & 3.053 & 0.444 & 4.225 & -0.592 & -5.305 & -1.961 & -1.535 & -1.320 & 1.885 & -1.073 \\
\hline $\mathrm{R} 2$ & 0.574 & 0.734 & 0.029 & 0.049 & 0.497 & 0.722 & 0.335 & 0.223 & 0.168 & 0.814 \\
\hline R2adj & 0.572 & 0.710 & 0.026 & -0.035 & 0.494 & 0.691 & 0.333 & 0.155 & 0.165 & 0.798 \\
\hline Boot p-val & 0.000 & 0.010 & 0.724 & 0.692 & 0.000 & 0.044 & 0.000 & 0.633 & 0.000 & 0.004 \\
\hline Corr-b1[t] & \multicolumn{2}{|c|}{0.887} & \multicolumn{2}{|c|}{-0.404} & \multicolumn{2}{|c|}{0.974} & \multicolumn{2}{|c|}{0.981} & \multicolumn{2}{|c|}{0.785} \\
\hline Corr-b2[t] & \multicolumn{2}{|c|}{0.936} & \multicolumn{2}{|c|}{-0.994} & \multicolumn{2}{|c|}{0.963} & \multicolumn{2}{|c|}{0.630} & \multicolumn{2}{|c|}{-0.770} \\
\hline Interact var & \multicolumn{2}{|c|}{ S\&P500 Total Return } & \multicolumn{2}{|c|}{ TED Spread } & \multicolumn{2}{|c|}{ TED Spread } & \multicolumn{2}{|c|}{ HML } & \multicolumn{2}{|c|}{ HML } \\
\hline
\end{tabular}




\section{Table IV}

\section{Results from a simulation study of the estimation method}

Table IV reports the mean and standard deviation, across 1000 independent simulation replications, of estimates of the parameters of a model of time-varying factor exposures. The results for ten different simulation designs are presented. Simulation design parameters are presented in the first panel of the table, and the mean and standard deviation of the simulation distribution of parameter estimates are presented in the second and third panels. The true values of the four parameters are presented in the first column of the table. The values for alpha, gamma and delta are scaled up by a factor of 100 for ease of interpretability.

\begin{tabular}{|c|c|c|c|c|c|c|c|c|c|c|c|c|}
\hline & & & 1 & 2 & 3 & 4 & 5 & 6 & 7 & 8 & 9 & 10 \\
\hline & & $\begin{array}{c}\text { True } \\
\text { values }\end{array}$ & $\begin{array}{c}\text { Base } \\
\text { scenario } \\
\end{array}$ & $\begin{array}{c}\text { Short } \\
\text { sample }\end{array}$ & $\begin{array}{c}\text { Long } \\
\text { sample } \\
\end{array}$ & $\begin{array}{c}\text { Low } \\
\text { autocorr } \\
\text { in } Z \\
\end{array}$ & $\begin{array}{c}\text { High } \\
\text { autocorr } \\
\text { in } \mathrm{Z} \\
\end{array}$ & $\begin{array}{c}\text { Corr } \\
\text { b/w F, } \\
Z\end{array}$ & $\begin{array}{c}\text { Neg } \\
\text { autocorr } \\
\text { in } \mathrm{F}, \\
\text { rhoFZ }=0\end{array}$ & $\begin{array}{c}\text { Pos } \\
\text { autocorr } \\
\text { in } \mathrm{F}, \\
\text { rhoFZ }=0\end{array}$ & $\begin{array}{c}\text { Neg } \\
\text { autocorr } \\
\text { in } \mathrm{F}, \\
\text { rhoFZ }=0.5\end{array}$ & $\begin{array}{c}\text { Pos } \\
\text { autocorr } \\
\text { in } \mathrm{F}, \\
\text { rhoFZ }=0.5 \\
\end{array}$ \\
\hline & $\mathrm{T}$ & & 60 & 24 & 120 & 60 & 60 & 60 & 60 & 60 & 60 & 60 \\
\hline & rhoFZ & & 0.0 & 0.0 & 0.0 & 0.0 & 0.0 & 0.5 & 0.0 & 0.0 & 0.5 & 0.5 \\
\hline & phiZ & & 0.5 & 0.5 & 0.5 & 0.0 & 0.9 & 0.5 & 0.5 & 0.5 & 0.5 & 0.5 \\
\hline & phiF & & 0.0 & 0.0 & 0.0 & 0.0 & 0.0 & 0.0 & -0.2 & 0.2 & -0.2 & 0.2 \\
\hline Mean & Alpha*100 & 0.758 & 0.715 & 0.827 & 0.794 & 0.729 & 0.773 & 0.812 & 0.780 & 0.735 & 0.725 & 0.721 \\
\hline Mean & Beta & 0.400 & 0.400 & 0.397 & 0.399 & 0.400 & 0.401 & 0.400 & 0.401 & 0.400 & 0.399 & 0.401 \\
\hline Mean & Gamma*100 & 0.200 & 0.198 & 0.198 & 0.200 & 0.198 & 0.200 & 0.200 & 0.199 & 0.201 & 0.198 & 0.199 \\
\hline Mean & Delta*100 & -0.400 & -0.391 & -0.400 & -0.409 & -0.399 & -0.404 & -0.410 & -0.381 & -0.392 & -0.397 & -0.394 \\
\hline St dev & Alpha*100 & & 0.089 & 0.146 & 0.062 & 0.089 & 0.092 & 0.194 & 0.085 & 0.091 & 0.191 & 0.191 \\
\hline St dev & Beta & & 0.035 & 0.060 & 0.024 & 0.033 & 0.035 & 0.035 & 0.042 & 0.031 & 0.041 & 0.029 \\
\hline St dev & Gamma*100 & & 0.005 & 0.009 & 0.003 & 0.008 & 0.003 & 0.005 & 0.006 & 0.004 & 0.005 & 0.004 \\
\hline St dev & Delta*100 & & 0.038 & 0.062 & 0.026 & 0.035 & 0.052 & 0.034 & 0.039 & 0.034 & 0.037 & 0.031 \\
\hline
\end{tabular}


Table V

Selection of Conditioning Variables

Table V shows results from the interaction-based model applied to the 14,194 funds in the data. In order, the columns report the variable name; the number of funds for which the conditioning variable is selected (the funds for which the variable beats all the other conditioning variables on the $\mathrm{R}^{2}$ criterion); the mean $\mathrm{R}^{2}$ from the benchmark constant-parameter factor model; the mean $\mathrm{R}^{2}$ from the factor model augmented with the selected conditioning variable; the ratio of the two $\mathrm{R}^{2 \text { s }} \mathrm{s}$; the number of funds for which the conditioning variable is significant using the bootstrap reality check; the average $\mathrm{R}^{2}$ from the benchmark and conditional factor models (and their ratio) only for those funds for which the conditioning variable is significant

\begin{tabular}{|c|c|c|c|c|c|c|c|c|c|}
\hline & \multirow[b]{2}{*}{ Variable } & \multicolumn{4}{|c|}{ Funds for which variable is selected } & \multicolumn{4}{|c|}{ Funds for which variable is significant } \\
\hline & & Number & Base R2 & Best R2 & Best/Base & Number & Base R2 & Best R2 & Best/Base \\
\hline 1 & $\mathrm{~d}($ Level) & 1370 & 0.289 & 0.459 & 1.588 & 465 & 0.383 & 0.624 & 1.631 \\
\hline 2 & Nasdaq Return & 758 & 0.300 & 0.472 & 1.577 & 249 & 0.400 & 0.650 & 1.626 \\
\hline 3 & USD/JPY Carry Trade Return & 958 & 0.289 & 0.455 & 1.575 & 243 & 0.397 & 0.666 & 1.677 \\
\hline 4 & $\mathrm{~d}$ (Slope) & 614 & 0.326 & 0.497 & 1.526 & 195 & 0.435 & 0.692 & 1.591 \\
\hline 5 & Fund Performance (3 months) & 1232 & 0.262 & 0.388 & 1.483 & 190 & 0.397 & 0.620 & 1.561 \\
\hline 6 & S \& P 500 Return & 634 & 0.304 & 0.469 & 1.540 & 186 & 0.397 & 0.644 & 1.622 \\
\hline 7 & TED Spread & 750 & 0.271 & 0.433 & 1.594 & 186 & 0.358 & 0.625 & 1.748 \\
\hline 8 & Variance Risk Premium & 645 & 0.301 & 0.470 & 1.558 & 186 & 0.407 & 0.663 & 1.629 \\
\hline 9 & BAAMTSY & 705 & 0.281 & 0.438 & 1.558 & 169 & 0.370 & 0.628 & 1.699 \\
\hline 10 & Fund Performance (1 month) & 1043 & 0.232 & 0.376 & 1.620 & 168 & 0.348 & 0.633 & 1.817 \\
\hline 11 & Realized Volatility: S\&P 500 & 628 & 0.274 & 0.441 & 1.607 & 164 & 0.391 & 0.638 & 1.630 \\
\hline 12 & VIX & 576 & 0.307 & 0.459 & 1.497 & 150 & 0.450 & 0.675 & 1.500 \\
\hline 13 & SMB & 734 & 0.261 & 0.402 & 1.543 & 130 & 0.419 & 0.658 & 1.568 \\
\hline 14 & HML & 578 & 0.265 & 0.429 & 1.617 & 125 & 0.390 & 0.669 & 1.714 \\
\hline 15 & UMD & 679 & 0.267 & 0.416 & 1.557 & 121 & 0.372 & 0.628 & 1.687 \\
\hline 16 & Turnover & 628 & 0.264 & 0.422 & 1.602 & 121 & 0.432 & 0.671 & 1.553 \\
\hline 17 & Realized Volatility: USD/JPY & 590 & 0.263 & 0.422 & 1.601 & 111 & 0.366 & 0.651 & 1.781 \\
\hline 18 & $\mathrm{~d}($ Curvature) & 625 & 0.246 & 0.394 & 1.601 & 90 & 0.345 & 0.633 & 1.834 \\
\hline \multirow[t]{2}{*}{19} & Amivest Ratio & 447 & 0.145 & 0.343 & 2.362 & 72 & 0.365 & 0.650 & 1.783 \\
\hline & Total/Average & 14194 & 0.272 & 0.431 & 1.611 & 3321 & 0.392 & 0.646 & 1.666 \\
\hline
\end{tabular}


Table VI

Evidence of Time-Varying Risk Exposures in Hedge Fund Returns

This table shows results from various tests for time-varying risk exposures in hedge fund returns. The first column shows the number of funds in each strategy, and the remaining columns report the proportion of funds for we can reject the null hypothesis of constant risk exposures at the 0.10 level, according to various models: the optimal changepoint regression approach of Bollen and Whaley (2009); the conditioning variables approach adopted in this paper; a model with the optimal changepoint included in the baseline two-factor model, and then the optimal conditioning variable being selected; the conditioning variables model estimated using only monthly variables. Panel A presents results based on bootstrap procedures described in Section 2.4. Panel B presents results when naive statistical procedures which fail to account for the search process are used instead of these bootstrap procedures.

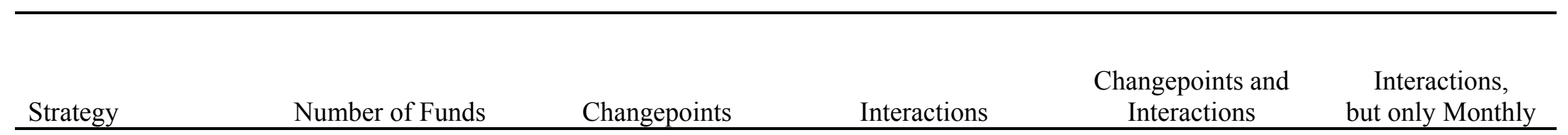

Panel A: Results based on bootstrap-based tests

\begin{tabular}{lccccc} 
Security Selection & 2942 & 0.229 & 0.200 & 0.263 & 0.131 \\
Macro & 885 & 0.215 & 0.116 & 0.179 & 0.084 \\
Relative Value & 146 & 0.144 & 0.240 & 0.322 & 0.158 \\
Directional Traders & 1813 & 0.240 & 0.266 & 0.326 & 0.189 \\
Fund of Funds & 3309 & 0.210 & 0.344 & 0.424 & 0.200 \\
Multi-Process & 1775 & 0.226 & 0.246 & 0.326 & 0.148 \\
Emerging & 478 & 0.186 & 0.176 & 0.232 & 0.117 \\
Fixed Income & 805 & 0.195 & 0.278 & 0.350 & 0.175 \\
CTA & 1981 & 0.187 & 0.110 & 0.154 & 0.083 \\
Other & 43 & 0.140 & 0.186 & 0.419 & 0.093 \\
\hline All & 14194 & 0.214 & 0.234 & 0.301 & 0.149 \\
\hline
\end{tabular}

Panel B: Results based on naive tests of significance 


\section{Table VII}

\section{Comparing Distributions of R-squared and Adjusted R-squared Statistics across Factor Models}

This table shows percentile points of the R-squared and Adjusted R-squared distributions across all 14,194 funds when applying the different methods to allow for time-varying factor loadings. The columns show the method employed for allowing for time-varying betas: The model with static factor loadings on the two best of the seven Fung-Hsieh factors selected per fund; the optimal changepoint regression approach; the conditioning variables (or "interactions") approach proposed in this paper; a model with the optimal changepoint included in the baseline two-factor model, and then the optimal interaction variable being selected; and finally, the interaction model estimated using only monthly interaction data. The rows show the statistic being computed; the top panel presents these statistics for R-squared; and the bottom panel presents these statistics for the Adjusted R-squared.

\begin{tabular}{|c|c|c|c|c|c|}
\hline & Static & Changepoints & Interactions & $\begin{array}{c}\text { Changepoints and } \\
\text { Interactions }\end{array}$ & $\begin{array}{c}\text { Interactions, } \\
\text { but only Monthly }\end{array}$ \\
\hline \multicolumn{6}{|c|}{ R-squared } \\
\hline $10^{\text {th }} \%$ & 0.076 & 0.179 & 0.189 & 0.278 & 0.177 \\
\hline $25^{\text {th }} \%$ & 0.141 & 0.255 & 0.285 & 0.382 & 0.263 \\
\hline Mean & 0.272 & 0.377 & 0.431 & 0.511 & 0.400 \\
\hline Median & 0.252 & 0.367 & 0.424 & 0.513 & 0.389 \\
\hline $75^{\text {th }} \%$ & 0.389 & 0.493 & 0.575 & 0.650 & 0.531 \\
\hline $90^{\text {th }} \%$ & 0.516 & 0.604 & 0.691 & 0.750 & 0.649 \\
\hline \multicolumn{6}{|c|}{ Adjusted R-squared } \\
\hline $10^{\text {th }} \%$ & 0.044 & 0.098 & 0.123 & 0.180 & 0.123 \\
\hline $25^{\text {th }} \%$ & 0.107 & 0.180 & 0.219 & 0.280 & 0.210 \\
\hline Mean & 0.244 & 0.311 & 0.371 & 0.425 & 0.352 \\
\hline Median & 0.223 & 0.301 & 0.361 & 0.422 & 0.339 \\
\hline $75^{\text {th }} \%$ & 0.365 & 0.436 & 0.520 & 0.573 & 0.487 \\
\hline $90^{\text {th }} \%$ & 0.497 & 0.557 & 0.645 & 0.687 & 0.614 \\
\hline
\end{tabular}


Table VIII

Selected Interaction Variables by Strategy

This table shows which interaction variables are most often statistically significant for each of the ten strategies listed in rows. For example, in the Security Selection strategy, $20 \%$ of funds have statistically significant interaction variables. Of these, $2.7 \%$ pick $\Delta$ Level as the interaction variable, $1.4 \%$ pick the USD/JPY Carry Trade return, and 1.2\% pick the momentum factor UMD. These three interaction variables are the three most often picked of the entire set of 19 interaction variables, across all individual funds in this strategy.

\begin{tabular}{|c|c|c|c|c|c|c|c|}
\hline \multirow{2}{*}{ Strategy } & \multirow[t]{2}{*}{ Perc. Sig } & \multicolumn{6}{|c|}{ Selection Rank } \\
\hline & & \multicolumn{2}{|l|}{ First } & \multicolumn{2}{|l|}{ Second } & \multicolumn{2}{|l|}{ Third } \\
\hline Security Selection & 0.200 & $\Delta$ Level & 0.027 & USD/JPY Carry Trade & 0.014 & UMD & 0.012 \\
\hline Global Macro & 0.116 & USD/JPY Carry Trade & 0.017 & S \& P 500 Total Return & 0.011 & $\Delta$ Level & 0.009 \\
\hline Relative Value & 0.240 & $\Delta$ Level & 0.055 & $\Delta$ Slope & 0.027 & BAAMTSY & 0.021 \\
\hline Directional Traders & 0.266 & $\Delta$ Level & 0.034 & USD/JPY Carry Trade & 0.023 & Fund Perf. (3 months) & 0.022 \\
\hline Funds of Funds & 0.344 & $\Delta$ Level & 0.066 & NASDAQ Return & 0.041 & $\Delta$ Slope & 0.024 \\
\hline Multi-Process & 0.246 & $\Delta$ Level & 0.034 & TED spread & 0.020 & Variance Risk Premium & 0.019 \\
\hline Emerging Markets & 0.176 & USD/JPY Carry Trade & 0.015 & Fund Perf. (1 month) & 0.015 & Fund Perf. (3 months) & 0.015 \\
\hline Fixed Income & 0.278 & Variance Risk Premium & 0.034 & TED Spread & 0.030 & Fund Perf. (1 month) & 0.025 \\
\hline CTAs & 0.110 & Fund Perf. (3 months) & 0.014 & Fund Perf. (1 month) & 0.013 & $\Delta$ Level & 0.008 \\
\hline Other & 0.186 & USD/JPY Carry Trade & 0.023 & Realized Volatility: S\&P 500 & 0.023 & NASDAQ Return & 0.023 \\
\hline All & 0.234 & $\Delta$ Level & 0.033 & NASDAQ Return & 0.018 & USD/JPY Carry Trade & 0.017 \\
\hline
\end{tabular}


Table IX

\section{Accounting for Time-Variation in Factor Exposures: Implications for Alpha}

The first two columns of Panel A of this table present means of the estimated annualized alphas from two different models, namely, the model with static factor loadings on the two best of the seven Fung-Hsieh factors selected per fund (1), and those from the conditioning variables (or "interactions") approach adopted in this paper (2). The third column shows the cross-sectional mean difference of these two alphas, the fourth column reports the cross-sectional mean of the absolute difference of these alphas, and the final column reports the cross-sectional rank correlation of these alphas. The rows show the cross-section of funds for which these statistics are computed: First, for all 14,194 funds; then for only the 3,321 funds for which the bootstrap test rejects the null hypothesis of constant risk exposures. Panel B shows the mean difference between the constant model alpha and the interactions model alpha broken out by strategy, for the subsample of funds with significant time-variation in risk exposures.

Panel A: Alpha Differences between Static Model and Interactions Model

\begin{tabular}{lccccc}
\hline & $\begin{array}{c}\text { Alpha From } \\
\text { Static Model }\end{array}$ & $\begin{array}{c}\text { Alpha From } \\
\text { Interactions Model }\end{array}$ & Difference & $\begin{array}{c}\text { Absolute Value } \\
\text { of Difference }\end{array}$ & Rank Correlation \\
& $(1)$ & $(2)$ & $(1)-(2)$ & $|(1)-(2)|$ & RankCorr[(1),(2)] \\
\hline All Funds & & & & & \\
Mean & 8.042 & 8.076 & -0.034 & 3.225 & 0.860 \\
t-stat & 70.991 & 67.504 & -0.594 & 63.987 & 201.180 \\
Funds w/Significant Time Variation & & & & & \\
Average & 6.527 & 7.029 & -0.502 & 4.588 & 0.736 \\
t-stat & 27.946 & 28.267 & -3.119 & 32.746 & 62.580 \\
\hline
\end{tabular}

Panel B: Strategy-Level Variation in Alpha Difference for Funds w/Significant Time Variation

\begin{tabular}{|c|c|c|c|c|c|c|c|c|c|c|c|}
\hline & $\begin{array}{c}\text { Sec. } \\
\text { Select. }\end{array}$ & Macro & $\begin{array}{c}\text { Rel. } \\
\text { Value }\end{array}$ & $\begin{array}{c}\text { Dir. } \\
\text { Traders }\end{array}$ & FoF & $\begin{array}{l}\text { Multi- } \\
\text { Proc. }\end{array}$ & Emerg & Fixed Inc. & CTA & Other & All \\
\hline N(Funds) & 589 & 103 & 35 & 483 & 1139 & 437 & 84 & 224 & 218 & 9 & 3321 \\
\hline Mean Alpha Diff. ((1)-(2)) & -0.584 & 1.073 & -1.867 & 0.765 & -0.725 & -1.492 & 4.816 & -0.928 & -0.089 & -2.054 & -0.502 \\
\hline t-stat & -1.221 & 1.488 & -2.497 & 1.655 & -4.007 & -3.796 & 2.311 & -2.178 & -0.063 & -2.397 & -3.119 \\
\hline
\end{tabular}


Table X

Robustness Checks

This table presents the proportion of funds with significant changepoints or interactions selected when the specification is altered according to the robustness checks itemized in the rows of the first column. The first row is taken from our main table of results (Table VI) and is repeated here for ease of reference. The first set of robustness checks splits the sample period into two halves; the second set alters the type of "unsmoothing" done to the returns prior to testing; the third set sorts funds according to their history lengths in the consolidated database; and the fourth set sorts funds according to their average assets under management.

\begin{tabular}{lcccc}
\hline Robustness Test & N(Funds) & Changepoints & Interactions & $\begin{array}{c}\text { Interactions, } \\
\text { but only monthly }\end{array}$ \\
\hline Main Results in Paper & 14194 & 0.214 & 0.234 & 0.149 \\
Sample Period & & & & \\
Earlier period (1994:01-2001:12) & 5618 & 0.226 & 0.174 & 0.11641 \\
Later period (2002:01-2009:06) & 11386 & 0.140 & 0.293 & 0.17284 \\
& & & & \\
Smoothing & 14194 & 0.276 & 0.248 & 0.145 \\
Raw returns (no GLM) & 14194 & 0.211 & 0.202 & 0.134 \\
Longer (4) MA lags in GLM model & & & & \\
& & & & 0.249 \\
Fund History Length & 2473 & 0.106 & 0.366 & 0.159 \\
24<=N(Fund Observations)<36 & 4409 & 0.138 & 0.252 & 0.110 \\
36<=N(Fund Observations)<60 & 7312 & 0.297 & 0.178 & \\
N(Fund Observations) $>=60$ & & & & 0.118 \\
Fund Size & & & 0.134 \\
Avg AUM <= 33rd Prctile & 3963 & 0.209 & 0.174 & 0.177 \\
33rd Prctile< Avg AUM <=66th Prctile & 4085 & 0.263 & 0.212 & \\
Avg AUM $>$ 66th Prctile & 3963 & 0.196 & & \\
\hline
\end{tabular}

